\title{
Modulation of Potassium Channel Activity in the Balance of ROS and ATP Production by Durum Wheat Mitochondria-An Amazing Defense Tool Against Hyperosmotic Stress
}

OPEN ACCESS

Edited by:

Ildikò Szabò,

University of Padova, Italy

Reviewed by:

Farida Minibayeva,

Kazan Institute of Biochemistry and Biophysics, Russia

Marco Zancani,

University of Udine, Italy

*Correspondence:

Donato Pastore

donato.pastore@unifg.it

Specialty section: This article was submitted to Plant Physiology,

a section of the journal

Frontiers in Plant Science

Received: 29 September 2015 Accepted: 16 November 2015 Published: 01 December 2015

Citation:

Trono D, Laus MN, Soccio M, Alfarano $M$ and Pastore D (2015) Modulation of Potassium Channel

Activity in the Balance of ROS and ATP Production by Durum Wheat Mitochondria-An Amazing Defense Tool Against Hyperosmotic Stress. Front. Plant Sci. 6:1072. doi: 10.3389/fp/s.2015.01072

\author{
Daniela Trono ${ }^{\text {, Maura N. Laus }}{ }^{2}$, Mario Soccio ${ }^{2}$, Michela Alfarano ${ }^{2}$ and Donato Pastore ${ }^{2 *}$ \\ 'Consiglio per la Ricerca in Agricoltura e l'Analisi dell'Economia Agraria, Centro di Ricerca per la Cerealicoltura, Foggia, \\ Italy, ${ }^{2}$ Dipartimento di Scienze Agrarie, degli Alimenti e dell'Ambiente, Università di Foggia, Foggia, Italy
}

In plants, the existence of a mitochondrial potassium channel was firstly demonstrated about 15 years ago in durum wheat as an ATP-dependent potassium channel $\left(\right.$ PmitoK $\left._{\mathrm{ATP}}\right)$. Since then, both properties of the original PmitoK ATP $_{\text {and occurrence }}$ of different mitochondrial potassium channels in a number of plant species (monocotyledonous and dicotyledonous) and tissues/organs (etiolated and green) have been shown. Here, an overview of the current knowledge is reported; in particular, the issue of PmitoK $\mathrm{K}_{\mathrm{ATP}}$ physiological modulation is addressed. Similarities and differences with other potassium channels, as well as possible cross-regulation with other mitochondrial proteins (Plant Uncoupling Protein, Alternative Oxidase, Plant

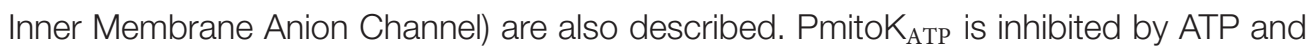
activated by superoxide anion, as well as by free fatty acids (FFAs) and acyl-CoAs. Interestingly, channel activation increases electrophoretic potassium uptake across the inner membrane toward the matrix, so collapsing membrane potential $(\Delta \Psi)$, the main component of the protonmotive force $(\Delta p)$ in plant mitochondria; moreover, cooperation between PmitoK $\mathrm{K}_{\mathrm{ATP}}$ and the $\mathrm{K}^{+} / \mathrm{H}^{+}$antiporter allows a potassium cycle able to dissipate also $\Delta \mathrm{pH}$. Interestingly, $\Delta \Psi$ collapse matches with an active control of mitochondrial reactive oxygen species (ROS) production. Fully open channel is able to lower superoxide anion up to 35-fold compared to a condition of ATP-inhibited channel. On the other hand, $\Delta \Psi$ collapse by PmitoK $\mathrm{ATP}_{\mathrm{P}}$ was unexpectedly found to not affect ATP synthesis via oxidative phosphorylation. This may probably occur by means of a controlled collapse due to ATP inhibition of PmitoK $\mathrm{ATP}_{\mathrm{AT}}$; this brake to the channel activity may allow a loss of the bulk phase $\Delta p$, but may preserve a non-classically detectable localized driving force for ATP synthesis. This ability may become crucial under environmental/oxidative stress. In particular, under moderate hyperosmotic stress (mannitol or $\mathrm{NaCl}$ ), PmitoK $\mathrm{K}_{\mathrm{ATP}}$ was found to be activated by ROS, so inhibiting further large-scale ROS production according to a feedback mechanism; moreover, a stress-activated phospholipase $A_{2}$ may generate FFAs, further activating the channel. In conclusion, a main property of PmitoK $\mathrm{ATP}_{\mathrm{A}}$ is the ability to keep in balance the control of harmful ROS with the mitochondrial/cellular bioenergetics, thus preserving ATP for energetic needs of cell defense under stress.

Keywords: plant mitochondria, potassium channel, oxidative phosphorylation, reactive oxygen species, hyperosmotic stress, durum wheat 


\section{THE MITOCHONDRIAL POTASSIUM CHANNELS FROM DURUM WHEAT AND OTHER PLANT SOURCES}

To date, there is evidence of the existence in plant mitochondria of at least four different types of $\mathrm{K}^{+}$channels (Table 1): the ATPsensitive $\mathrm{K}^{+}$channels (PmitoK $\mathrm{ATP}_{\text {and }}$ ather similar); the $\mathrm{K}^{+}$ channel insensitive to ATP; the large conductance $\mathrm{K}^{+}$channel activated by $\mathrm{Ca}^{2+}\left(\right.$ mitoBK $\left._{\mathrm{Ca}}\right)$; the large conductance $\mathrm{K}^{+}$channel insensitive to $\mathrm{Ca}^{2+}$ and sensitive to iberiotoxin (mitoBK).

\section{ATP-sensitive $\mathrm{K}^{+}$Channels}

The existence of a $\mathrm{K}^{+}$channel has been demonstrated for the first time in mitochondria from etiolated seedlings of durum wheat. This was achieved by means of measurements of decrease of electrochemical membrane potential $(\Delta \Psi)$ due to externally added $\mathrm{K}^{+}$to energized mitochondria, as well as by swelling experiments in which $\mathrm{K}^{+}$influx into mitochondria was checked by monitoring absorbance decrease of mitochondrial suspension in isosmotic $\mathrm{KCl}$ solution (Pastore et al., 1999). The channel was found to be an ATP-sensitive $\mathrm{K}^{+}$channel and was named Plant mitoK $\mathrm{K}_{\mathrm{ATP}}$ channel $\left(\mathrm{PmitoK}_{\mathrm{ATP}}\right)$ in analogy with the animal counterpart, the mito $\mathrm{K}_{\mathrm{ATP}}$. In durum wheat mitochondria (DWM) the PmitoK ${ }_{\text {ATP }}$-mediated $\Delta \Psi$ decrease is specifically induced by $\mathrm{K}^{+}\left(\mathrm{Cs}^{+}\right.$and $\left.\mathrm{Rb}^{+}\right)$, whereas it is less evident in the presence of $\mathrm{Na}^{+}$or $\mathrm{Li}^{+}$; the rate of $\mathrm{K}^{+}$uptake by DWM shows a hyperbolic dependence on the $\mathrm{K}^{+}$concentration with a $\mathrm{Km}$ of about $2 \mathrm{mM}$, which is significantly lower compared to the value of $32 \mathrm{mM}$ measured for the mitoK $\mathrm{K}_{\mathrm{ATP}}$ purified from rat liver mitochondria (Paucek et al., 1992). Moreover, the $\mathrm{K}^{+}$transport through the PmitoK $\mathrm{K}_{\mathrm{ATP}}$ depends on $\Delta \Psi$; notably, the channel is activated by hyperpolarization with a fast increase of activity between 140 and $175 \mathrm{mV}$. Similarly to the animal counterpart, the PmitoK $_{\text {ATP }}$ is inhibited by ATP and, to a lesser extent, by ADP; it is also activated by diazoxide and by thiol-group reagents, such as mersalyl and $\mathrm{N}$-ethylmaleimide (NEM). Contrarily to mitoK $\mathrm{ATP}_{\mathrm{AT}}$, the PmitoK $\mathrm{K}_{\mathrm{ATP}}$ does not require $\mathrm{Mg}^{2+}$ for the ATP inhibition, it is activated rather than inhibited by palmitoyl-CoA and it is not inhibited by glyburide. The PmitoK $\mathrm{K}_{\mathrm{ATP}}$ also differs from plant inward rectifying channels of non-mitochondrial membranes as it is not inhibited by $\mathrm{Al}^{3+}, \mathrm{Ba}^{2+}$, and $\mathrm{TEA}^{+}$. Activation by CoA and inhibition by NADH and $\mathrm{Zn}^{2+}$ are typical features of the PmitoK $_{\text {ATP }}$ (Pastore et al., 1999).

In DWM, the PmitoK $\mathrm{ATP}_{\mathrm{AT}}$ is highly active and may cooperate with the $\mathrm{K}^{+} / \mathrm{H}^{+}$antiporter. The operation of a $\mathrm{K}^{+} / \mathrm{H}^{+}$exchanger in mammalian mitochondria has long been known (for review, see Bernardi, 1999; Xu et al., 2015), with the molecular identity in yeast and humans proposed by Zotova et al. (2010). The existence of a very active $\mathrm{K}^{+} / \mathrm{H}^{+}$antiporter has been reported also in plant mitochondria (Diolez and Moreau, 1985) and some potential candidate genes have been reported by
Sze et al. (2004). In DWM, the occurrence of a negligible $\Delta \mathrm{pH}$ and of a high $\Delta \Psi$ is in line with the existence of a powerful $\mathrm{K}^{+} / \mathrm{H}^{+}$antiporter (Trono et al., 2011). The cooperation between PmitoK $\mathrm{K}_{\mathrm{ATP}}$ and $\mathrm{K}^{+} / \mathrm{H}^{+}$antiporter allows the operation of a $\mathrm{K}^{+}$cycle that causes the re-entry of $\mathrm{H}^{+}$into the matrix, thus collapsing the proton motive force $(\Delta \mathrm{p})$ (Pastore et al., 1999; Trono et al., 2004, 2011) by dissipating, in particular, the $\Delta \Psi$, which represents the main part of $\Delta \mathrm{p}$ in plant mitochondria (Douce, 1985; Figure 1). Interestingly, it has been demonstrated that the rate-limiting step of the $\mathrm{K}^{+}$cycle is represented by the electrophoretic $\mathrm{K}^{+}$influx via PmitoK $\mathrm{ATP}_{\mathrm{ATP}}$ (Pastore et al., 1999). In this respect, PmitoK $_{\mathrm{ATP}}$ strongly differs from the mammalian counterpart. Indeed, in mammalian mitochondria the $\mathrm{K}^{+}$cycle cannot uncouple completely, because the maximal rate of the cycle, that corresponds to the $\mathrm{V}_{\max }$ of the $\mathrm{K}^{+} / \mathrm{H}^{+}$antiporter, is only about $20 \%$ of the maximal rate of proton ejection by the respiratory chain (Garlid and Paucek, 2003). Indeed, in heart mitochondria, the increased $\mathrm{K}^{+}$influx associated to $\mathrm{K}^{+}$channel opening is small and it was found to depolarize by only $1-2 \mathrm{mV}$ (Kowaltowski et al., 2001). In rat liver mitochondria some $\Delta \Psi$ decrease was observed which depended on $\mathrm{KCl}$ concentration (up to about $20 \mathrm{mV}$ at $100 \mathrm{mM} \mathrm{KCl}$ ), but it was compensated by an increase in $\Delta \mathrm{pH}$ so that the $\Delta \mathrm{p}$ remained almost constant (Czyz et al., 1995).

The patch clamp technique, for the first time successfully applied to plant mitochondria, confirmed the existence in DWM of a cation channel inhibited by ATP, probably referable to the

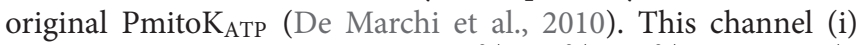
is inhibited by ATP but not by $\mathrm{Mg}^{2+}, \mathrm{Ba}^{2+}, \mathrm{Ca}^{2+}$, and $\mathrm{TEA}^{+}$, (ii) does not discriminate between $\mathrm{K}^{+}$and $\mathrm{Na}^{+}$, (iii) has a conductance of $150 \mathrm{pS}$, (iv) has a strong voltage dependence and rectification.

In addition to the PmitoK $\mathrm{K}_{\mathrm{ATP}}$ from DWM, the existence of ATP-sensitive $\mathrm{K}^{+}$channels has been afterward demonstrated by different research groups in mitochondria from different plant species and tissues/organs: pea stem (Petrussa et al., 2001), soybean suspension cell cultures (Casolo et al., 2005), embryonal masses of two coniferous species (Petrussa et al., 2008a), Arum spadix and tuber (Petrussa et al., 2008b), potato tuber (Matkovic et al., 2011) and potato cell cultures (Fratianni et al., 2001).

As for the $\mathrm{K}^{+}$selective and ATP-inhibited $\mathrm{K}^{+}$channel identified in pea stem mitochondria, evidence has been reported about its sensitivity to cyclosporine A (CsA; Petrussa et al., 2001), which has led to the assumption that it is involved in programmed cell death (PCD). In line with this hypothesis, the authors showed that, in these mitochondria, $\mathrm{K}^{+}$channel activation with CsA causes the rupture of the outer mitochondrial membrane and an increase in permeability transition of the inner membrane with consequent release of pyridine nucleotides and cytochrome $c$ from mitochondria (Chiandussi et al., 2002; Petrussa et al., 2004). The involvement of the $\mathrm{K}^{+}$channel in mitochondrial swelling

Abbreviations: ADP/O, ratio between phosphorylated ADP and reduced oxygen; AOX, Alternative Oxidase; ATP D.S., ATP detecting system; CsA, cyclosporine A; DWM, durum wheat mitochondria; FFA, free fatty acid; IMAC, Inner Membrane Anion Channel; NEM, $N$-ethylmaleimide; NO, nitric oxide; OXPHOS,

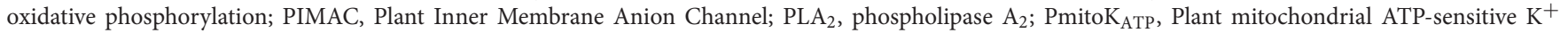
channel; PCD, programmed cell death; PUCP, Plant Uncoupling Protein; RC, respiratory control; RNS, reactive nitrogen species; ROS, reactive oxygen species; UCP, Uncoupling Protein; $\Delta \mathrm{p}$, proton motive force; $\Delta \Psi$, electrochemical membrane potential. 
TABLE 1 | Plant mitochondrial $\mathrm{K}^{+}$channels and their main modulators.

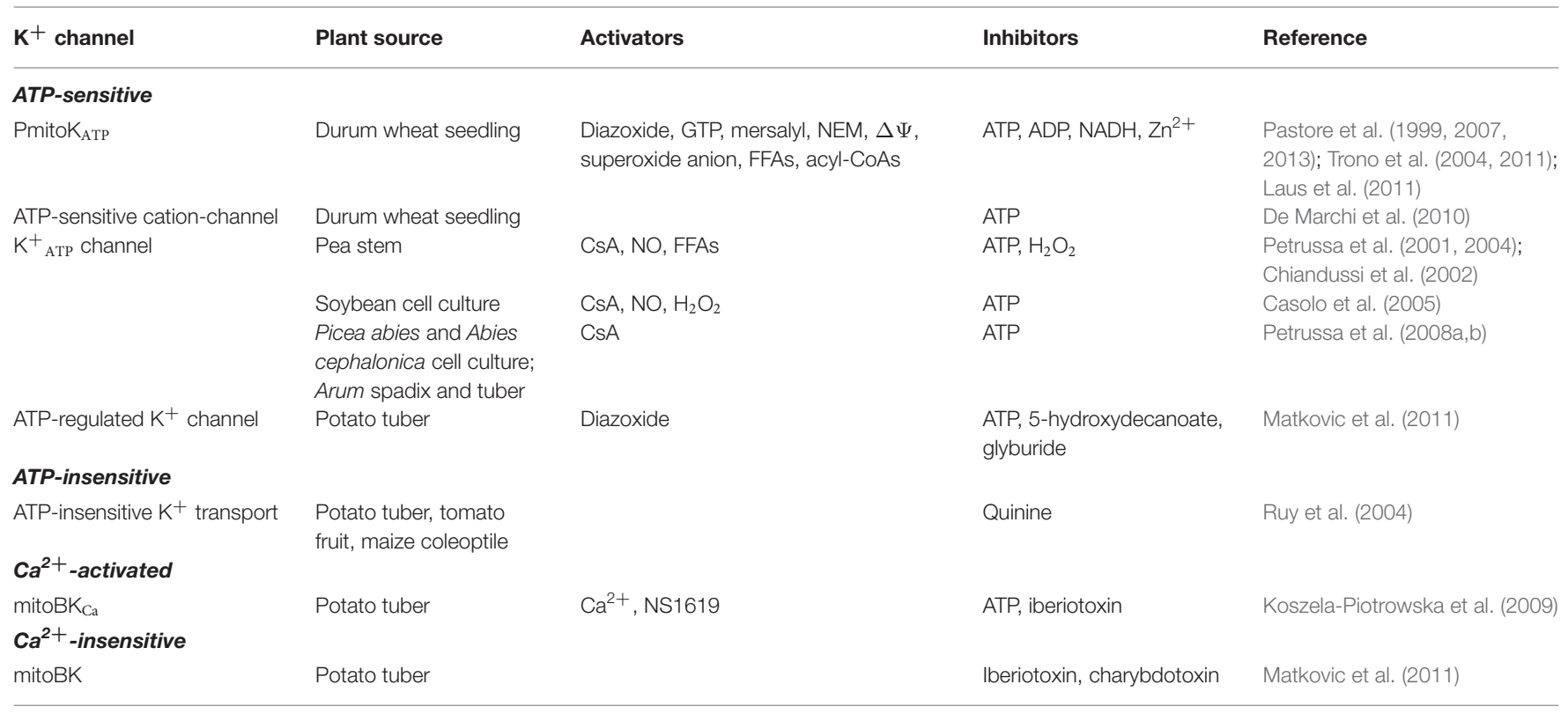

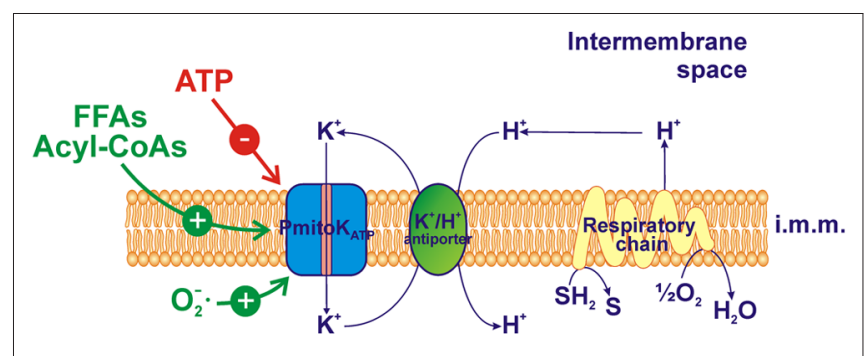

Matrix

FIGURE 1 | PmitoK ATP $_{\text {functioning and modulation in durum wheat }}$ mitochondria (DWM). PmitoK $\mathrm{ATP}_{\text {TP }}$ catalyzes the electrophoretic $\mathrm{K}^{+}$uptake across the inner membrane toward the matrix, so lowering membrane potential; the cooperation between PmitoK $_{\mathrm{ATP}}$ and the $\mathrm{K}^{+} / \mathrm{H}^{+}$antiporter allows a $\mathrm{K}^{+}$cycle able to dissipate also $\Delta \mathrm{pH}$, the second component of the proton motive force generated by the respiratory chain. ATP inhibits the channel while free fatty acids (FFAs), acyl-CoAs and superoxide anion activate it. The reducing equivalent flux through the respiratory chain to molecular oxygen and the coupled proton ejection into the intermembrane space are also indicated. The topology of ATP, FFAs, acyl-CoAs and ROS interaction with PmitoK $\mathrm{K}_{\mathrm{ATP}}$ is not considered. $\mathrm{SH}_{2}$, reduced substrates; $\mathrm{S}$, oxidized substrates; i.m.m., inner mitochondrial membrane.

and cytochrome $c$ release has been confirmed during $\mathrm{H}_{2} \mathrm{O}_{2}$ induced or NO-induced PCD of soybean suspension cell cultures (Casolo et al., 2005). A role of $\mathrm{K}^{+}$channel in thermogenic tissues has also been postulated. Notably, Arum spadix mitochondria possess a highly active $\mathrm{K}^{+}$channel, which mediates $\mathrm{K}^{+}$influx only when the over-reduction of the electron transport chain is lowered by Alternative Oxidase (AOX); under this condition, $\mathrm{K}^{+}$ accumulation inside mitochondria mediated by the $\mathrm{K}^{+}$channel may contribute to prevent mitochondrial shrinkage consequent to the non-coupled respiration (Petrussa et al., 2008b).

An ATP-regulated $\mathrm{K}^{+}$channel with a conductance of $164 \mathrm{pS}$ has also been detected in potato tuber mitochondria by Matkovic et al. (2011). Similarly to mitoK $\mathrm{K}_{\mathrm{ATP}}$, this channel causes low $\mathrm{K}^{+}$ influx, which leads to a modest decrease in $\Delta \Psi$ (up to a few $\mathrm{mV}$ ); moreover, it is activated by diazoxide and blocked by ATP, 5-hydroxydecanoate and glyburide.

\section{ATP-insensitive $\mathrm{K}^{+}$Channels}

A highly active ATP-insensitive $\mathrm{K}^{+}$channel has been described in potato, tomato and maize mitochondria (Ruy et al., 2004). This channel has a greater selectivity for $\mathrm{K}^{+}$compared to PmitoK $\mathrm{ATP}_{\mathrm{AT}}$, it is insensitive to NADH, 5-hydroxydecanoate and glyburide, typical modulators of ATP-sensitive $\mathrm{K}^{+}$channels, and it is sensitive to quinine, a broad-spectrum inhibitor of $\mathrm{K}^{+}$channels. Similarly to the PmitoK $\mathrm{ATP}_{\text {, }}$ the ATP-insensitive $\mathrm{K}^{+}$channel allows the import of large quantities of $\mathrm{K}^{+}$inside mitochondria; this determines a significant increase in the respiration rate in state 4 , that could potentially lead to a reduction in the ability of phosphorylation of these mitochondria.

\section{Large-conductance $\mathrm{Ca}^{2+}$-activated $\mathrm{K}^{+}$Channel}

Six years ago, for the first time, the existence of a largeconductance (502-615 pS) and $\mathrm{Ca}^{2+}$-activated $\mathrm{K}^{+}$channel in mitochondria from potato tuber was shown by KoszelaPiotrowska et al. (2009). The authors demonstrated that, in the presence of $\mathrm{KCl}$ and under conditions in which the ATP-sensitive $\mathrm{K}^{+}$channels are inhibited by ATP, a decrease of $\Delta \Psi$ occurs, which is stimulated by both $\mathrm{Ca}^{2+}$ and NS1619, this latter being an opener of $\mathrm{BK}_{\mathrm{Ca}}$ channels, and inhibited by iberiotoxin, an inhibitor of both plasma membrane $\mathrm{K}^{+}$channels and $\mathrm{BK}_{\mathrm{Ca}}$.

\section{Large-conductance $\mathrm{Ca}^{2+}$-insensitive $\mathrm{K}^{+}$Channel}

Mitochondria from potato tubers also possess a largeconductance $(312 \mathrm{pS})$ and $\mathrm{Ca}^{2+}$-insensitive $\mathrm{K}^{+}$channel (mitoBK; 
Matkovic et al., 2011). Similarly to the mitoBK $\mathrm{Ca}_{\mathrm{a}}$ channel, the mitoBK channel is inhibited by iberiotoxin. Charybdotoxin, another $\mathrm{K}^{+}$channel blocker, also inhibits the potato tuber mitoBK channel. The authors reported evidence that, under phosphorylating conditions, the coupling parameters of potato tuber mitochondria remain unchanged in the presence of high $\mathrm{K}^{+}$level, thus indicating that the $\mathrm{K}^{+}$channel present in these mitochondria functions as energy-dissipating system that is not able to divert energy from oxidative phosphorylation (OXPHOS).

It is noteworthy that the occurrence of some $\mathrm{K}^{+}$pathways has been demonstrated by swelling experiments in mitochondria from other plant species and tissues/organs, including (i) etiolated seedlings of bread wheat, spelt, rye, barley and lentil, (ii) green leaves of triticale, maize, spinach and durum wheat, (iii) pea roots, (iv) potato and topinambur tubers (Pastore et al., 1999; Laus et al., 2011). However, to date, no information is available about ATP and/or $\mathrm{Ca}^{2+}$ modulation of these $\mathrm{K}^{+}$pathways.

\section{Molecular Identities of Mitochondrial $\mathrm{K}^{+}$Channels}

In spite of the important role of mitochondrial $\mathrm{K}^{+}$channels in cell physiology, knowledge of their molecular identities is difficult to obtain; so it proceeds only slowly and remains still limited.

Information about the molecular structure of PmitoK $\mathrm{ATP}_{\mathrm{A}}$ and other plant mitochondrial $\mathrm{K}^{+}$channels is still very scarce and molecular identity remains unknown. At our best knowledge, only a report is available that regards the partial purification from potato of a mitoK $K_{\mathrm{ATP}}$, which was suggested to contain Kir and SUR type subunits (Paucek et al., 2002). The identification by means of a proteomic approach of a $\beta$ regulatory subunit of a $\mathrm{Kv}$ channel has also been reported in rice mitochondria (Tanaka et al., 2004), although the identity of the channel associated with it remains unknown. With regard to possible candidate genes, a strong mitochondrial targeting is predicted for the Shaker-type Kv genes AKT1 or AKT1-like in several plant species, including barley, grape, rice and bread wheat, but not Arabidopsis thaliana (De Marchi et al., 2010). In particular, in wheat root an AKT1-like channel with a strong prediction of mitochondrial localization has been cloned (Buschmann et al., 2000). In addition, only one Kirlike channel has been identified in the $A$. thaliana genome, which is the single-pore $\mathrm{K}^{+}$channel AtKCO3. However, this channel does not show any sequence homology with Kir6.1 and Kir6.2 and its mitochondrial targeting is predicted with low probability and only by some localization prediction tools (De Marchi et al., 2010).

With regard to the PmitoK $\mathrm{K}_{\mathrm{ATP}}$, some hypotheses about the possible molecular identity of this channel have been proposed based on its electrophysiological properties. In particular, the voltage dependence of the DWM channel prompted the authors to propose that it might correspond to the single-pore KCO3 channel (De Marchi et al., 2010), although this proposal is in contrast with the high conductance and the high permeability to $\mathrm{Na}^{+}$ of the observed channel activity. The possibility that the DWM channel may be a Shaker-like channel with altered characteristics, such as the lack of $\beta$-subunit or, alternatively, the presence of another regulatory protein, may be also considered. In particular, one possibility may be that an ABC-transporter protein is associated with AtKCO3 or AKT1-like subunits to give rise to the ATP-dependent DWM channel activity. Moreover, in the light of both the high conductance and the poor selectivity for $\mathrm{K}^{+}$over $\mathrm{Na}^{+}$, the possibility that the observed DWM channel may be a non-selective cation channel (NSCC) cannot be excluded (De Marchi et al., 2010).

As for other plant mitochondrial $\mathrm{K}^{+}$channels, immunological studies have suggested the molecular identity of the ATPregulated $\mathrm{K}^{+}$channel (Matkovic et al., 2011) and of the mitoBK $\mathrm{Ca}$ (Koszela-Piotrowska et al., 2009) detected in potato tuber mitochondria by electrophysiological studies (see above). Indeed, immunoreactivity with antibodies raised against the human poreforming subunits of the Kir6.0-family, as well as against the $\alpha$ - and $\beta$-subunits of the mammalian plasma membrane $\mathrm{BK}_{\mathrm{Ca}}$ channel, has confirmed the presence in these mitochondria of an ATP-regulated $\mathrm{K}^{+}$channel and of a large-conductance $\mathrm{Ca}^{2+}$-activated iberiotoxin-sensitive $\mathrm{K}^{+}$channel, structurally similar to the mammalian mitoK $\mathrm{ATP}_{\mathrm{AT}}$ and mitoBK $\mathrm{Ca}_{\mathrm{a}}$ channels, respectively (Koszela-Piotrowska et al., 2009; Matkovic et al., 2011).

Substantial efforts are still needed to achieve the molecular identification of plant mitochondrial $\mathrm{K}^{+}$channels.

\section{PHYSIOLOGICAL MODULATORS OF THE PmitoK $\mathrm{K}_{\text {ATP }}$}

\section{Inhibition by ATP}

As said above, PmitoK $\mathrm{K}_{\mathrm{ATP}}$ activity is inhibited by ATP, with the inhibition occurring at the outer side of the inner membrane (Laus et al., 2008; Figure 1). ATP inhibition of PmitoK $\mathrm{ATP}_{\mathrm{ATP}}$ does not require the presence of $\mathrm{Mg}^{2+}$ ions (Pastore et al., 1999; De Marchi et al., 2010), so differing from the mammalian

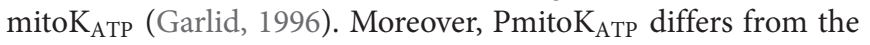
mammalian counterpart for another important aspect of ATP inhibition. The mitoK $K_{A T P}$ activity is strongly inhibited by very low ATP concentrations, with half inhibition of 22-40 $\mu \mathrm{M}$ (Garlid, 1996; Garlid and Paucek, 2003); this suggests that the degree of mitoK $\mathrm{K}_{\mathrm{ATP}}$ opening in vivo should be not easily modulated by ATP (Garlid and Paucek, 2003), whose concentration in mammalian cells falls in the millimolar range. Conversely, PmitoK $_{\text {ATP }}$ affinity for ATP is significantly lower (from 10to 15 -fold) than that of the mammalian counterpart. Indeed, a non-competitive inhibition by ATP on the PmitoK $\mathrm{ATP}_{\mathrm{AT}}$ was observed with a Ki of about $0.3 \mathrm{mM}$ (Pastore et al., 1999); consistently, a $\mathrm{K}_{0.5}$ of $0.5 \mathrm{mM}$ was measured by patch clamp technique (De Marchi et al., 2010). These results suggest a possible PmitoK $\mathrm{K}_{\mathrm{ATP}}$ regulation by ATP in vivo. With respect to this point, the nucleotide triphosphate concentration measured in plant cell by means of NMR analysis is $0.9-1.2 \mathrm{mM}$ (Gout et al., 1992). Moreover, about $70 \%$ of nucleotide triphosphate concentration is formed by ATP, as measured in perchloric acid extract (Roby et al., 1987). Considering these data, a cytosolic ATP concentration of $0.6-0.8 \mathrm{mM}$ may be assumed. Moreover, it should be also considered that the apparent $\mathrm{Km}$ for $\mathrm{K}^{+}$ uptake by PmitoK $\mathrm{ATP}_{\mathrm{AT}}$ is $2.2 \mathrm{mM}$ (Pastore et al., 1999) and that plant mitochondria show a high cytosolic $\mathrm{K}^{+}$concentration 
homeostatically maintained at high levels $(80-100 \mathrm{mM}$; Leigh and Wyn Jones, 1984). In the light of these data, and on the basis of a rough calculation according to the Michaelis-Menten equation, a PmitoK ${ }_{\text {ATP }}$ functioning equal to $20-45 \%$ of the maximal activity could be reached at physiological ATP concentrations; moreover, a change of channel functioning may be expected as a response to changing ATP concentrations. Consistently, in different mitochondrial preparations, in the presence of $0.7,0.5$ and $0.3 \mathrm{mM}$ ATP, an activation of PmitoK $\mathrm{K}_{\mathrm{ATP}}$ was measured with respect to $0.9 \mathrm{mM}$ ATP condition, equal to $25.3 \pm 4.3 \%$, $37.2 \pm 3.2 \%, 44.7 \pm 7.4 \%$ (SE, $n=4$ ), respectively; in the absence of ATP, the activation was equal to $184.7 \pm 13.2 \%$ (Soccio et al., 2013).

It is noteworthy that, among the mitochondrial dissipative systems, ATP inhibition is not a peculiar characteristic of

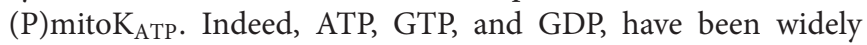
demonstrated to act as inhibitors of Uncoupling Proteins (UCPs) from animal and plant sources (Hourton-Cabassa et al., 2004). As far as DWM is concerned, ATP is the main inhibitor of Plant Uncoupling Protein (PUCP), while GDP and GTP are less effective (Pastore et al., 2000). In particular, $0.5 \mathrm{mM}$ ATP was found to determine an inhibition of about $70 \%$ of the rate of the linoleate-induced $\Delta \Psi$ decrease in succinate-respiring mitochondria; consistently, in mitochondria depolarized by linoleate, $30 \mu \mathrm{M}$ ATP was able to cause about $50 \% \Delta \Psi$ recovery (Pastore et al., 2000). Moreover, in DWM, ATP at physiological concentrations was found to strongly inhibit (45-85\%) also the Plant Inner Membrane Anion Channel (PIMAC), probably acting at the outer side of the inner membrane (Laus et al., 2008). So, ATP counteracts the transport of both $\mathrm{K}^{+}$and $\mathrm{Cl}^{-}$through the inner membrane of DWM. A strong ATP inhibition (50-80\%) was also observed on the PIMAC of topinambur tuber mitochondria (Laus et al., 2008).

\section{Activation by ROS}

In the plant cell, mitochondria and chloroplasts represent the major site of reactive oxygen species (ROS) generation. In particular, the Complex I and especially the Complex III of the mitochondrial electron transport chain are involved in the non-enzymatic one-electron reduction of molecular oxygen to generate superoxide anion; at the level of the Complex III superoxide anion may be released not only into the matrix but also on the outer side of the inner mitochondrial membrane (Blokhina and Fagerstedt, 2010). A key role in the superoxide anion production is played by the redox state of the ubiquinone pool. In fact, ubiquinone over-reduction increases the lifetime of the ubisemiquinone radical, which, in turn, promotes single electron transfer to molecular oxygen, so generating superoxide anion. Superoxide anion produced in the mitochondrial matrix may generate $\mathrm{H}_{2} \mathrm{O}_{2}$ in an enzymatic reaction catalyzed by a matrix-localized $\mathrm{Mn}$-superoxide dismutase. Plant mitochondria are known to generate also reactive nitrogen species (RNS). In particular, nitrite reduction to nitric oxide (NO) occurs at Complex III and Complex IV of the electron transport chain (Igamberdiev et al., 2014).

The activation of a mitochondrial $\mathrm{K}^{+}$channel by superoxide anion has been reported for the first time in DWM (Pastore et al., 1999; Figure 1). In particular, an about 100\% stimulation

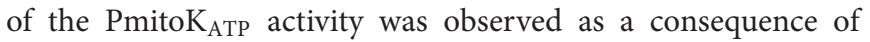
mitochondria incubation with the superoxide anion-producing system, consisting of xanthine plus xanthine oxidase. Moreover, a partial prevention of activation was observed when the reaction medium was added with superoxide dismutase, able to remove superoxide anion. Two years later, activation by superoxide anion has also been reported for the mammalian mitoK $\mathrm{ATP}_{\mathrm{ATP}}$ by Zhang et al. (2001a). The authors found that reconstituted myocardial mitoK $\mathrm{K}_{\mathrm{ATP}}$ was markedly activated by superoxide anion and that the activation was completely prevented by pretreatment with the sulfhydryl alkylating compound NEM. This result suggests that the activation by superoxide anion of the mitoK $\mathrm{K}_{\mathrm{ATP}}$ may be dependent on its direct action on the sulfhydryl groups of the channel protein. Successively, in isolated rat heart mitochondria the mitoK $\mathrm{K}_{\mathrm{ATP}}$ activity was found to be strongly enhanced by stimulation of endogenous mitochondrial ROS generation or mitochondrial treatment with $\mathrm{H}_{2} \mathrm{O}_{2}$; this occurred in a manner probably dependent on redox sensors located in the sulfonylurea receptor of the channel (Facundo et al., 2007). On the other side, evidence has been reported that in rat heart mitochondria the mito $\mathrm{K}_{\mathrm{ATP}}$ is not activated by superoxide anion but it is activated indirectly by $\mathrm{NO}$ and $\mathrm{H}_{2} \mathrm{O}_{2}$, through the activation of protein kinase $\mathrm{C} \varepsilon$ (Costa and Garlid, 2008). A direct activation of the mitoK $\mathrm{K}_{\mathrm{ATP}}$ by NO was instead observed in cardiac submitochondrial particles (Ljubkovic et al., 2007).

With regard to other plant mitochondria, a regulation of the $\mathrm{K}^{+}$channels by ROS and RNS has also been reported in pea steam mitochondria (Chiandussi et al., 2002). Notably, in these mitochondria the $\mathrm{K}^{+}$ATP channel resulted to be inhibited by $\mathrm{H}_{2} \mathrm{O}_{2}$ and activated by NO. As already observed for the animal counterpart, also in pea steam mitochondria the NOinduced activation of the $\mathrm{K}^{+}$channel may be dependent on a nitrothiosylation reaction occurring between $\mathrm{NO}^{+}$and specific sulfhydryl groups present in the protein forming the channel (Chiandussi et al., 2002).

It should be outlined that in plants a regulation by ROS and RNS was also observed on $\mathrm{K}^{+}$channels located in plasma membranes. Indeed, in A. thaliana, hydroxyl radical was found to induce a large outward-rectifying $\mathrm{K}^{+}$current attributed to GORK, a guard cell-type constitutive outward-rectifying root plasma membrane $\mathrm{K}^{+}$channel (Demidchik et al., 2010), whereas heterologously expressed SKOR was found to be modulated by $\mathrm{H}_{2} \mathrm{O}_{2}$ (GarciaMata et al., 2010). Also, Xia et al. (2014) recently demonstrated that NO lowers AKT1 channel-mediated $\mathrm{K}^{+}$uptake in A. thaliana root cells by modulating vitamin $\mathrm{B} 6$ biosynthesis, whereas a NO-induced up-regulation of the AKT1 gene was reported in mangrove plant, which contributes to $\mathrm{K}^{+} / \mathrm{Na}^{+}$balance (Chen et al., 2013).

As far as the effect of ROS and RNS on other plant mitochondrial dissipative systems, an activation of PUCP by both $\mathrm{H}_{2} \mathrm{O}_{2}$ and superoxide anion has been reported in DWM (Pastore et al., 2000) and topinambur (Paventi et al., 2006). Indeed, the addition of $\mathrm{H}_{2} \mathrm{O}_{2}$ and superoxide anion to succinate-respiring DWM, partially depolarized by low linoleate concentrations $(4-8 \mu \mathrm{M})$, was found to determine a further and complete 
$\Delta \Psi$ collapse; moreover, when $\mathrm{H}_{2} \mathrm{O}_{2}$ or superoxide anion was added before $8 \mu \mathrm{M}$ linoleate, the linoleate-induced $\Delta \Psi$ decrease occurred to a higher extent and at a higher rate (about $40 \%)$. To date, no information about PUCP modulation by NO is available; nevertheless, sensitivity of PUCP activity to changes of $S$-nitrosoglutathione reductase levels has been recently reported in $A$. thaliana transgenic cell lines, thus suggesting that PUCP activity might be modulated by nitrosothiols/NO content (Frungillo et al., 2013). Moreover, in suspension cells of Petunia hybrida (Wagner, 1995) and tobacco (Vanlerberghe and McIntosh, 1996), AOX gene expression was found to be induced by $\mathrm{H}_{2} \mathrm{O}_{2}$. Conversely, in DWM, AOX activity was demonstrated to be insensitive to $\mathrm{H}_{2} \mathrm{O}_{2}$ and superoxide anion, while activation was found to be dependent on photorespiratory and malate metabolism (Pastore et al., 2001, 2003). Similarly, the lack of effect of NO on the AOX activity (Millar and Day, 1996) and its ability to induce AOX gene expression (Huang et al., 2002) were reported. However, although ROS may act as activators of some transport pathways, it should be underlined that an excess of harmful ROS also causes inhibition of some other transports in DWM (Pastore et al., 2002).

\section{Activation by Free Fatty Acids and Acyl-CoAs}

As demonstrated by means of swelling experiments in $\mathrm{KCl}$ solutions, linoleate and other free fatty acids (FFAs), including the non-physiological 1-undecanesulphonate and 5-phenylvalerate, added to isolated DWM at a concentration of $10 \mu \mathrm{M}$, activated $\mathrm{K}^{+}$uptake via PmitoK $\mathrm{ATP}_{\text {p }}$ by 2-4-fold (Laus et al., 2011; Figure 1). The FFA-induced activation of PmitoK $\mathrm{K}_{\mathrm{ATP}}$ is not associated to the depletion of endogenous $\mathrm{Mg}^{2+}$, so differing from that of the mammalian $\mathrm{K}^{+}$channels (Schönfeld et al., 2003 and references therein). Also in pea stem mitochondria FFAs appear to stimulate the $\mathrm{K}^{+}$ATP channel activity in dissipating $\Delta \Psi$ (Table 1, Petrussa et al., 2004). Regulation by FFAs in plants is observed on plasma membrane $\mathrm{K}^{+}$channels, too; in particular, in guard cells, FFAs have been reported to activate the inwardly rectifying $\mathrm{K}^{+}$channel and to inhibit the outward $\mathrm{K}^{+}$channel (Lee et al., 1994).

Interestingly, in DWM, $\mathrm{K}^{+}$transport, evaluated by swelling experiments, was also found to be stimulated by acyl-CoA esters (Figure 1). The acyl-CoA-mediated stimulation of $\mathrm{K}^{+}$uptake resulted much higher (5-12-fold) than that induced by the corresponding FFAs (Laus et al., 2011). With regard to acylCoAs, PmitoK $\mathrm{ATP}_{\mathrm{AT}}$ behavior differs from that of the rat liver mitoK $\mathrm{K}_{\mathrm{ATP}}$, whose activity is strongly inhibited by palmitoylCoA and oleoyl-CoA (Garlid, 1996; Paucek et al., 1996), and more closely resembles that of mammalian plasma membrane $\mathrm{K}_{\mathrm{ATP}}$ channels. Indeed, acyl-CoAs represent one of the main classes of activators of plasma membrane ATP-regulated $\mathrm{K}^{+}$ channels in pancreatic beta cells (Bränström et al., 2007 and references therein; Webster et al., 2008 and references therein) and cardiac muscle cells (Liu et al., 2001; Schulze et al., 2003).

The FFA/acyl-CoA-induced stimulation of $\mathrm{K}^{+}$transport observed in DWM by means of swelling experiments was also confirmed by $\Delta \Psi$ measurements. Indeed, the addition to succinate-respiring DWM of 5-phenylvalerate or palmitoyl-CoA, both unable to activate the PUCP, was found to stimulate the depolarization induced by $\mathrm{K}^{+}$uptake via PmitoK $\mathrm{K}_{\mathrm{ATP}}$. This stimulation was partially recovered/prevented by the addition of ATP, thus suggesting that FFAs/acyl-CoAs are activators of PmitoK $_{\mathrm{ATP}}$ able to modulate its sensitivity to ATP (Laus et al., 2011). It is noteworthy that this stimulation is enhanced when FFAs and acyl-CoAs are present together. Indeed, when palmitate at concentrations ranging between 20 and $50 \mathrm{nmol} \mathrm{mg}^{-1}$ of protein was added to DWM suspended in a $\mathrm{KCl}$ medium containing palmitoyl-CoA at a physiological concentration $(2.5 \mu \mathrm{M})$ (Larson and Graham, 2001), a synergistic action was observed able to determine a very strong activation (up to 11 -fold) of PmitoK $\mathrm{ATP}_{\mathrm{AT}}$. Moreover, activation of $\mathrm{K}^{+}$transport by FFAs/acyl-CoAs resulted a property common to other plant mitochondria isolated from different mono/dicotyledonous species, including bread wheat, barley, triticale, maize, lentil, pea and topinambur, as well as from different organs, such as root, tuber, leaf and shoot (Laus et al., 2011).

Interestingly, PmitoK $\mathrm{ATP}_{\mathrm{AP}}$ activation was also observed after addition to DWM of small amount of a bee venom phospholipase $\mathrm{A}_{2} \quad\left(\mathrm{PLA}_{2}\right)$, an enzyme able to specifically hydrolyze membrane phospholipids at the $s n-2$ position to yield FFAs and lysophospholipids. This suggests that activation of PmitoK $_{\text {ATP }}$ by FFAs/acyl-CoAs may occur in vivo as a result of endogenous generation of FFAs from membrane phospholipids and their metabolism (Laus et al., 2011). The recent discovery of a PLA $\mathrm{P}_{2}$ activity in DWM and mitochondria from other plant species (barley, spelt, maize and tomato) and tissues/organs (tuber and green and etiolated seedlings; Trono et al., 2013) is in line with the proposed physiological regulation of $\mathrm{Pmito}_{\mathrm{ATP}}$ by FFAs/acyl-CoA derivatives.

With regard to other dissipative systems, FFAs are known to be strictly required for UCP activation in both plant and animal mitochondria (for reviews, see Vercesi et al., 2006; Echtay, 2007). Moreover, Sluse et al. (1998) reported that FFAs may act as AOX inhibitors. In addition to dissipative systems, long-chain FFAs have also been reported to activate the Inner Membrane Anion Channel (IMAC), the $\mathrm{K}^{+}$uniport and the $\mathrm{K}^{+} / \mathrm{H}^{+}$antiport in rat liver mitochondria (Schönfeld et al., 2003, 2004). Recently, stimulation by polyunsaturated FFAs of mitoBK $\mathrm{Ca}_{\mathrm{Ca}}$ halso been reported in human astrocytoma U87 MG cell lines (Olszewska et al., 2014). With regard to DWM, it has been shown that these mitochondria possess a so active PUCP that very low FFA concentrations $(8-12 \mu \mathrm{M})$ are enough to quickly and completely collapse $\Delta \Psi$ (Pastore et al., 2000, 2007). Besides the dissipative systems, also DWM-PIMAC was found to be inhibited by unsaturated and, to a lesser extent, saturated FFAs (Laus et al., 2008), an opposite behavior compared to the animal counterpart. In practice, in DWM, FFAs activate $\mathrm{K}^{+}$, but inhibit $\mathrm{Cl}^{-}$uptake; this behavior may limit excess swelling and inner membrane rupture under physiological conditions that induce PLA $\mathrm{P}_{2}$ activation and high FFA generation. Moreover, no inhibition of DWM-PIMAC was observed in the presence of acyl-CoA esters (Laus et al., 2008), although palmitoyl-CoA is known to inhibit IMAC (Halle-Smith et al., 1988). 


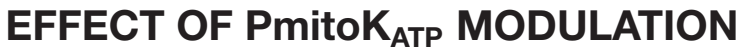 ON MITOCHONDRIAL ROS PRODUCTION AND ATP SYNTHESIS VIA OXIDATIVE PHOSPHORYLATION}

\section{Activation of PmitoK $\mathrm{K}_{\mathrm{ATP}}$ and Control of ROS Production}

A dramatic stimulation of mitochondrial generation of superoxide anion and other harmful ROS is induced by high $\Delta \Psi$ values and by an over-reduction state of the respiratory chain components. So, according to the "mild uncoupling" theory proposed by Skulachev $(1994,1998)$, a lowering of $\Delta \Psi$ may markedly decrease superoxide anion generation, so protecting mitochondria from high ROS production. Consistently, evidence has been reported that, in DWM, the activation of PmitoK $\mathrm{K}_{\mathrm{ATP}}$ may lower superoxide anion generation by controlling $\Delta \Psi$ levels. In particular, in DWM that oxidized succinate in $0.5 \mathrm{mM} \mathrm{KCl}$ medium, the rate of superoxide anion generation was equal to $42 \pm 8.8 \mathrm{nmol} \mathrm{min}-1$ $\mathrm{mg}^{-1}$ of protein; this rate was lowered to $22 \pm 5.6 \mathrm{nmol} \mathrm{min}{ }^{-1}$ $\mathrm{mg}^{-1}$ of protein when mitochondria were suspended in a medium at high $(100 \mathrm{mM}) \mathrm{KCl}$ concentration (Pastore et al., 1999). Moreover, in DWM that oxidized ascorbate plus $N, N, N^{\prime}, N^{\prime}$ tetramethyl-p-phenylenediamine, the activation of PmitoK $\mathrm{K}_{\mathrm{ATP}}$ by $\mathrm{KCl}$ plus mersalyl almost completely abolished the superoxide anion generation. This is not surprising, since, as reported above, PmitoK $\mathrm{ATP}_{\text {TP }}$ may act together with the active $\mathrm{K}^{+} / \mathrm{H}^{+}$antiporter, thus allowing the operation of a $\mathrm{K}^{+}$cycle able to induce a $\Delta \Psi$ collapse that, in turn, may lower the mitochondrial ROS generation.

The capability to control mitochondrial ROS generation is not a peculiar property of the $\mathrm{PmitoK}_{\mathrm{ATP}}$, but it is common to other plant mitochondrial $\mathrm{K}^{+}$channels. Notably, in pea stem mitochondria, the activation of the $\mathrm{K}^{+}{ }_{\text {ATP }}$ channel by CsA and its inhibition by ATP were found to increase and to decrease, respectively, the depolarization induced by the channel functioning and, consequently, to decrease and to increase the mitochondrial $\mathrm{H}_{2} \mathrm{O}_{2}$ production. However, the prevention of ROS production was observed only in pea stem mitochondria respiring succinate and not in those oxidizing malate plus glutamate, thus indicating that, in these mitochondria, the operation of the channel is able to control only the ROS generation at the level of the Complex III (Casolo et al., 2003). Also in potato tuber mitochondria, the activation of the ATP-insensitive $\mathrm{K}^{+}$ transport was found to induce a decrease in the mitochondrial $\mathrm{H}_{2} \mathrm{O}_{2}$ generation (Ruy et al., 2004).

With respect to ROS control, PmitoK $\mathrm{ATP}_{\mathrm{AT}}$ may differ from the mammalian counterpart due to the fact that in mammalian mitochondria the $\mathrm{K}^{+}$cycle is very low and causes a negligible depolarization (see above). So, in rat heart mitochondria an increase in ROS generation was even observed as a consequence of mitoK $K_{\text {ATP }}$ activation (Garlid et al., 2013 and references therein). On the other hand, in the same mitochondria an opposite behavior was reported by Facundo et al. (2005), who showed an inhibition of ROS production due to mitoK $\mathrm{ATP}_{\text {activation; }}$ similarly, inhibition of ROS production was also reported for mitochondria of other mammalian tissues, e.g., brain (Ferranti et al., 2003), liver (Alberici et al., 2009) and spleen (Alberici et al., 2013). These controversial findings in mammalian mitochondria may be dependent on different experimental conditions and effects of $\mathrm{K}^{+}$channel on $\Delta \Psi$.

Many other energy-dissipating systems in plant and animal mitochondria have been proposed to efficiently control mitochondrial ROS generation (Kowaltowski et al., 2009; Blokhina and Fagerstedt, 2010). As for purified DWM, PUCP and AOX activation was demonstrated to dampen mitochondrial ROS production. In particular, in succinate-respiring mitochondria a $45 \%$ decrease of superoxide anion generation rate was observed in the presence of externally added linoleate, able to activate PUCP (Pastore et al., 2000); this effect was prevented by the addition of bovine serum albumin, able to remove FFAs. Similarly, AOX activation by externally added pyruvate in DWM respiring malate plus glutamate was found to reduce by half the rate of superoxide anion generation; the inhibition of AOX by propylgallate restored the rate of superoxide anion generation to the levels measured in the absence of pyruvate (Pastore et al., 2001).

On the whole, in vitro modulation of PmitoK $\mathrm{ATP}_{\mathrm{AT}}$ due to externally added ATP, FFAs/acyl-CoAs and ROS regulates the mitochondrial $\Delta \Psi$ and ROS generation. Notably, as shown in Figure 2, ATP addition to DWM inhibits PmitoK $_{\text {ATP }}$ and, consequently, the $\mathrm{K}^{+}$cycle; this generates a high $\Delta \Psi$ and a high ROS production (Figure 2A). On the contrary, the addition of FFAs and/or their acyl-CoA derivatives, as well as of ROS, which all activate PmitoK $_{\mathrm{ATP}}$, determines an increase in the rate of the $\mathrm{K}^{+}$cycle, thus leading to a decrease in $\Delta \Psi$ and ROS production (Figure 2B).

\section{Unexpected Lack of Inhibition on ATP Synthesis in DWM Depolarized by PmitoK}

In isolated DWM, PmitoK $\mathrm{ATP}_{\mathrm{P}}$ activity is able to collapse $\Delta \Psi$, but unexpectedly the loss of $\Delta \mathrm{p}$ is unable to inhibit ATP synthesis via OXPHOS (Trono et al., 2011). Indeed, succinate-respiring DWM, added with $25 \mathrm{mM} \mathrm{KCl}$, showed a very low $\Delta \Psi$, but both the ATP synthesis and the coupling were found to be not affected. These results were obtained by using three different approaches, that is (i) the continuous monitoring of the ATP synthesis and efflux outside DWM by using an enzymatic ATP detecting system (ATP D.S.), (ii) the enzymatic measurement of the ATP synthesized at the end of a phosphorylation cycle, (iii) the oxygraphic determination of the respiratory control (RC) ratio and of the ratio between phosphorylated ADP and reduced oxygen $(\mathrm{ADP} / \mathrm{O})$. The first approach allowed calculation of a rate of ATP appearance outside DWM of $193 \pm 11.8 \mathrm{nmol}$ $\mathrm{min}^{-1} \mathrm{mg}^{-1}$ of protein and $221 \pm 15.1 \mathrm{nmol} \mathrm{min}-1 \mathrm{mg}^{-1}$ of protein, respectively, in the absence and in the presence of $\mathrm{KCl}$ addition, thus suggesting that no significant difference exists between control and $\mathrm{KCl}$-depolarized DWM. This observation was confirmed by the result obtained with the second approach, in which DWM synthesized ATP in the absence of the ATP D.S. and this latter was added at the end of the reaction to assay the amount of ATP produced. Both control and $\mathrm{KCl}$-depolarized DWM were able to completely convert $50 \mu \mathrm{M}$ ADP into ATP, thus confirming 
A

\section{Intermembrane \\ space}

High $\Delta \Psi$

High ROS
Intermembrane

space
B

Low $\triangle \Psi$

Low ROS

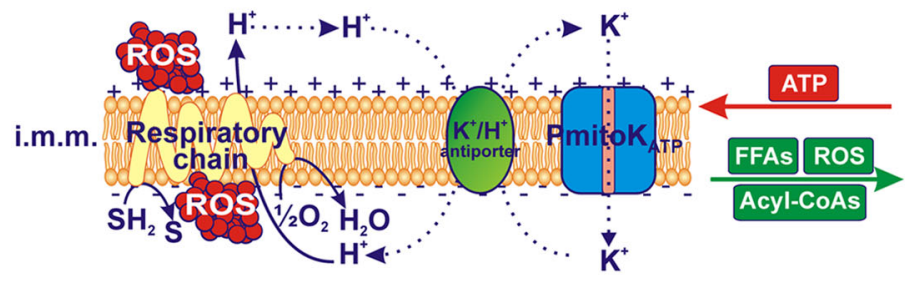

Matrix

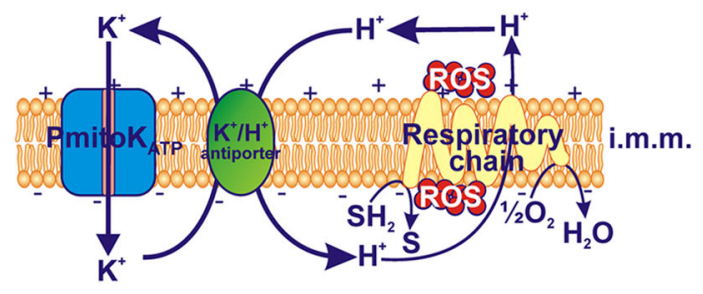

Matrix

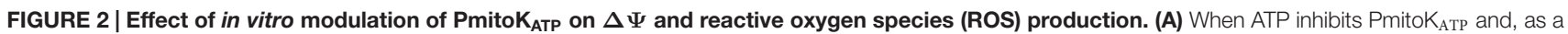
consequence, the $\mathrm{K}^{+}$cycle due to the PmitoK $\mathrm{ATP}_{\mathrm{A}}-\mathrm{K}^{+} / \mathrm{H}^{+}$antiporter combined function, both high electrical membrane potential $(\Delta \Psi)$ and high $\mathrm{ROS}$ production are observed. (B) On the contrary, in the presence of FFAs and their acyl-CoA derivatives, as well as of ROS, which activate PmitoK $\mathrm{ATP}_{\mathrm{P}}$, $\mathrm{K}^{+}$cycle is activated and both

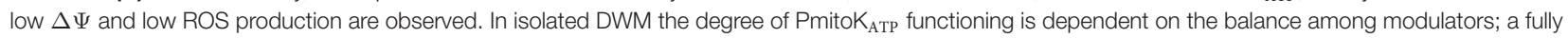
opened channel may completely collapse $\Delta \Psi$ and ROS production. The reducing equivalent flux through the respiratory chain to molecular oxygen and the coupled proton ejection into the intermembrane space are also indicated; + and - signs refer to $\Delta \Psi$. The continuous or dotted arrows refer to a more or less active pathway, respectively. $\mathrm{SH}_{2}$, reduced substrates; $\mathrm{S}$, oxidized substrates; i.m.m., inner mitochondrial membrane.

similar phosphorylative capacity. Finally, the third oxygraphic approach allowed to assess that $\mathrm{KCl}$-depolarized DWM retain $\mathrm{RC}$ and $\mathrm{ADP} / \mathrm{O}$ ratios similar to those observed in the absence of $\mathrm{KCl}$ addition. Moreover, the rate of ATP synthesis, calculated by multiplying the $\mathrm{ADP} / \mathrm{O}$ ratio by the corresponding state 3 oxygen uptake rate (Krömer and Heldt, 1991; Flagella et al., 2006), was $190 \pm 6.5 \mathrm{nmol} \mathrm{min}{ }^{-1} \mathrm{mg}^{-1}$ of protein and $190 \pm 11.0$ nmol $\mathrm{min}^{-1} \mathrm{mg}^{-1}$ of protein, respectively, in the absence and in the presence of $\mathrm{KCl}$ addition, thus further confirming that the activation of PmitoK $\mathrm{ATP}_{\mathrm{A}}$ in $\mathrm{KCl}$-treated DWM does not affect the ATP synthesis via OXPHOS. In the same experiments, as internal controls, classical modes of uncoupling induced by the addition of FCCP, $\mathrm{KCl}$ plus valinomycin or linoleate, were found to cause fast and complete $\Delta \Psi$ dissipation, as well as a complete impairment of ATP synthesis (Trono et al., 2011).

In order to verify whether a possible increase of $\Delta \mathrm{pH}$ may compensate the lack of $\Delta \Psi$ to sustain ATP synthesis, measurements of the internal $\mathrm{pH}$, carried out by loading DWM with the fluorescent probe bis-carboxyethyl-5(6)carboxyfluorescein acetoxymethyl ester, were performed to calculate $\Delta \mathrm{pH}$. Results showed that no $\Delta \mathrm{pH}$ increase occurs caused by $\mathrm{KCl}$ addition to mitochondria and that the ATP synthesis via OXPHOS takes place in the absence of a classically measurable $\Delta \mathrm{p}$ (Trono et al., 2011). Interestingly, these measurements also confirmed that in DWM $\Delta \mathrm{pH}$ is negligible as in other plant mitochondria and that $\Delta \Psi$ largely represents the main component of $\Delta \mathrm{p}$ (Douce, 1985). A major prediction of the chemiosmotic model is that the phosphorylation potential and the rate of ATP synthesis should depend on the magnitude of the "delocalized" bulk water phase $\Delta \mathrm{p}$. So, it is feasible that the ATP synthesis via OXPHOS in KCl-depolarized DWM should not occur according to the classical chemiosmotic model. Indeed, evidence has been gathered that some energy-transducing membranes trouble this chemiosmotic model in favor of a "localized" theory. For instance, in Halobacterium halobium light induced an increase in the ATP synthesis without a concomitant increase in $\Delta \mathrm{pH}$ and $\Delta \Psi$ (Michel and Oesterhelt, 1980), whereas in thylakoid vesicles photophosphorylation was found to occur in the absence of both $\Delta \Psi$ and $\Delta \mathrm{pH}$ (Ort et al., 1976). Also, extreme alkaliphilic bacteria from the Bacillus species synthesized ATP even in the presence of a very low $\Delta \mathrm{p}$ due to the adverse $\mathrm{pH}$ gradient, alkaline outside (Krulwich, 1995 and references therein), whereas in bovine heart submitochondrial particles a decrease in the ATP synthesis was observed as a consequence of the inhibition of the respiration rate, despite $\Delta \mathrm{p}$ remained constant (Sorgato et al., 1980). Moreover Castrejón et al. (1997) reported that, at low phosphate concentration, the addition of $\mathrm{KCl}$ to yeast mitochondria caused a $\Delta \mathrm{p}$ collapse, while the rate of ATP synthesis by OXPHOS was maintained at high level (about $60 \%$ of that measured in the absence of $\mathrm{KCl}$ ). In all these papers, the authors converge on the idea that these unusual behaviors are not readily accommodated within a simple chemiosmotic scheme, but an alternative mechanism for the transfer of protons from the respiratory chain to ATP synthase may be invoked.

Consistently, the existence of a "localized" rather than a "delocalized" energy transfer between the complexes of the respiratory chain and the ATP synthase that does not involve the bulk water phase was postulated by Tedeschi (2005a,b). Consistently, Heberle et al. (1994) reported that protons ejected by an integral membrane protein can move laterally along the membrane surface so to reach the usual entry site for protons in the ATP synthase; this long-range proton transfer was found to occur at a rate higher compared to the exchange with the bulk 


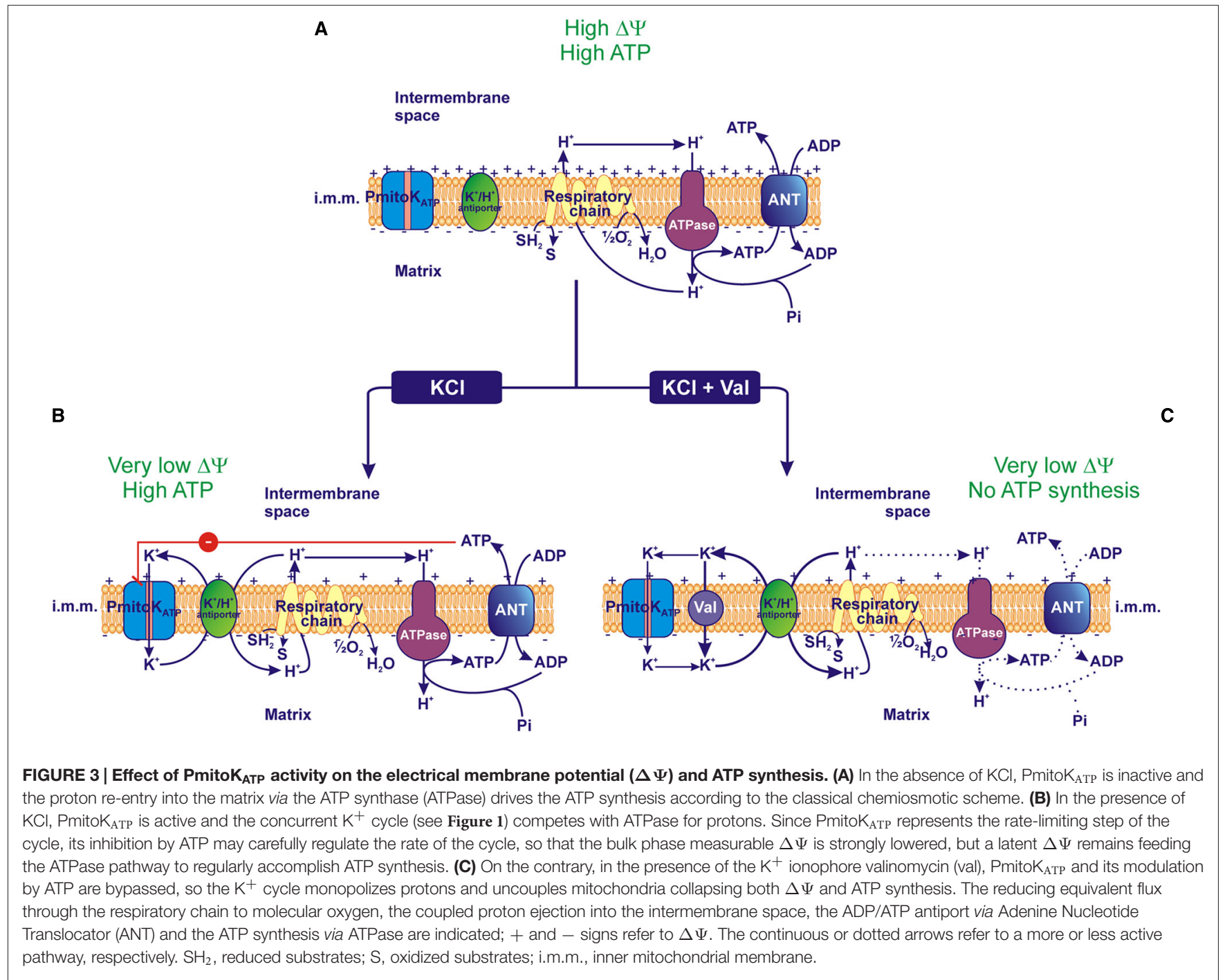

water phase. Alternatively, studies dealing with the interaction between the cytochrome $\mathrm{caa}_{3}$ respiratory chain complex and the $\mathrm{F}_{1}$ Fo-ATP synthase in the extremely alkaliphilic Bacillus pseudofirmus OF4 suggested that proton transfer may occur as a direct proton transfer within the membrane during proteinprotein interaction probably due to a physical association between the two complexes (Liu et al., 2007).

In this context, the behavior of Pmito $\mathrm{K}_{\mathrm{ATP}}$-depolarized DWM represents the first evidence of isolated plant mitochondria that lack measurable $\Delta \Psi$ and $\Delta \mathrm{pH}$, but, at the same time, are fully coupled and regularly accomplish ATP synthesis via OXPHOS. A possible explanation of this finding may reside

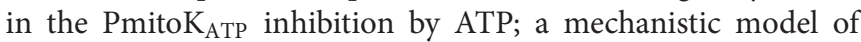
this coupling in the absence of measurable bulk phase $\Delta \Psi$ and $\Delta \mathrm{pH}$ is represented in Figure 3. In DWM suspended in a $\mathrm{KCl}$-free medium the $\mathrm{PmitoK}_{\mathrm{ATP}}$ is inactive and mitochondria accomplish ATP synthesis according to classical chemiosmosis (Figure 3A). On the other hand, in the presence of $\mathrm{KCl}$ and ATP, a PmitoK $K_{\text {ATP }}$ activity exists, but it is inhibited, thus reducing the whole rate of the $\mathrm{K}^{+}$cycle; so, a "controlled collapse" is achieved that avoids complete uncoupling. In particular, this ATP-braked activity of PmitoK $\mathrm{K}_{\mathrm{ATP}}$ may strongly reduce the classically detectable bulk phase $\Delta \mathrm{p}$, but in such a manner to only partially subtract protons to ATP synthase and to retain a latent proton movement, able to sustain ATP synthesis and transport (Pastore et al., 2013; Trono et al., 2014; Figure 3B). Consistently, in the presence of valinomycin, the ATP brake of PmitoK $\mathrm{K}_{\mathrm{ATP}}$ activity is overcome, so exacerbating $\mathrm{K}^{+}$cycle; under this condition, complete uncoupling occurs, preventing ATP synthesis (Figure 3C). In practice, while the classical uncouplers are unable to distinguish among different proton pools, somehow the PmitoK $\mathrm{K}_{\mathrm{ATP}}$ /ATP system appears to be able to distinguish the bulk phase $\Delta \mathrm{p}$ from a non-classically detectable driving force for ATP synthesis.

In the light of the above results, it was proposed that, in vivo, PmitoK $\mathrm{K}_{\mathrm{ATP}}$ functioning should not affect $\mathrm{RC}$ and $\mathrm{ADP} / \mathrm{O}$ ratios, as well as the rate of ATP synthesis, while an evident effect on $\Delta \mathrm{p}$ is expected because mitochondria truly interface with a high cytosolic $\mathrm{KCl}$ concentration (Trono et al., 2011). At this regard, it is interesting to note that the $\Delta \Psi$ values determined in vitro 
on isolated $\mathrm{KCl}$-suspended DWM correspond to $60-100 \mathrm{mV}$ in different experiments, that mach well with those measured in vivo; therefore, it is feasible that results in DWM depict a physiological condition. Indeed, in plant cells, Igamberdiev and Kleczkowski (2003) applied a new method to evaluate mitochondrial $\Delta \Psi$ from the subcellular ATP/ADP ratios by means of rapid subcellular fractionation of barley leaf protoplasts and calculated values of 70-95 mV under different physiological conditions. In animals, Zhang et al. (2001b) used a conventional fluorescence microscopy combined with three dimensional deconvolution by exhaustive photon reassignment and measured a mitochondrial $\Delta \Psi$ of about $105 \mathrm{mV}$ in fibroblasts and $81 \mathrm{mV}$ in neuroblastoma cells. In addition, in perfused hearts (Wan et al., 1993) and single hepatocytes (Ubl et al., 1996) $\Delta \Psi$ values of $100-140 \mathrm{mV}$ were measured under different metabolic conditions. So, these findings clearly show that, in living cells, mitochondria have a low or very low $\Delta \Psi$, and that ATP synthesis may, however, occur at suboptimal $\Delta \Psi$.

\section{PmitoK $_{\text {ATP }}$ AS DWM DEFENSE SYSTEM UNDER HYPEROSMOTIC STRESS}

A possible physiological role of the PmitoK $_{\text {ATP }}$ under environmental/oxidative stresses derives from its property to act as energy-dissipating system able to control $\Delta \Psi$, ATP synthesis and, above all, ROS production. It is well known that cellular ROS production can be increased as a result of plant exposure to various environmental stresses (Scandalios, 1993; Foyer et al., 1994; Møller, 2001); mitochondria, in particular, are known to increase ROS generation under drought and salt stress (Alscher et al., 1997). Consistently, in DWM purified from hyperosmotically (mannitol or $\mathrm{NaCl}$ ) stressed seedlings, an increase in the rate of superoxide anion production of about $40 \%$ and $120 \%$ with respect to the control was found under moderate and severe stress conditions, respectively (Trono et al., 2004). In particular, stress was considered moderate when a starting oxidative stress was observed, without a concomitant damage on substrate oxidation, ATP synthesis and mitochondria intactness. On the other hand, it was considered as severe a stress that induced a drop of substrate oxidation (Trono et al., 2004; Soccio et al., 2010), ATP synthesis (Flagella et al., 2006) and, consequently, a remarkable ATP content decrease (Trono et al., 2011; Soccio et al., 2013), as well as some loss of outer membrane integrity (Trono et al., 2004; Soccio et al., 2010). All these findings were obtained on mitochondria isolated from stressed seedlings in which PmitoK $\mathrm{K}_{\mathrm{ATP}}$ was maintained essentially inactive by carrying out measurements in $\mathrm{KCl}$-free or low- $\mathrm{KCl}$ media. On the other hand, when the channel was activated under stress, it was found to deeply affect ROS and ATP production (Figure 4).

In the absence of an external stress (Figure 4A), mitochondria may synthesize ATP via OXPHOS at high rate and ROS are generated at a basal level; consequently, in the balance between ATP and activators, that include ROS and FFAs/acylCoAs, ATP inhibition of the PmitoK $\mathrm{K}_{\mathrm{ATP}}$ activity is expected to prevail, thus allowing only basal activity of the channel. The picture changes under stress conditions. Under moderate hyperosmotic stress (Figure 4B), the increase of ROS production by mitochondria may activate $\mathrm{PmitoK}_{\mathrm{ATP}}$, which, in turn, according to a feedback mechanism, may dampen excess ROS production as described above. Moreover, evidence has been reported that the mitochondrial $\mathrm{PLA}_{2}$ activity, recently detected in DWM, is activated by hyperosmotic stress (but not via ROS) and it has been proposed to determine the increase in vivo of both FFAs and their acyl-CoA derivatives, which further enhance the channel activation (Trono et al., 2013). Consistently, PmitoK $\mathrm{ATP}_{\mathrm{AT}}$ activity was found to increase by $57 \%$ and $300 \%$ under $\mathrm{NaCl}$ and mannitol moderate stress, respectively (Trono et al., 2004). Consistently, PmitoK $\mathrm{K}_{\mathrm{ATP}}$ may significantly lower ROS production: in in vitro measurements, a mersalyl-activated channel was found to be able to reduce up to 35 -fold the rate of superoxide anion generation (Trono et al., 2011).

The most intriguing aspect of PmitoK $\mathrm{K}_{\mathrm{ATP}}$ functioning under moderate stress condition regards its regulation of ATP synthesis. Channel opening for the control of ROS production necessarily implies a $\Delta \Psi$ decrease up to a complete collapse (Figure 2); as a consequence, a strong inhibition of ATP synthesis via OXPHOS should be observed. Conversely, as stated above, under these experimental conditions, the ATP synthesis is unexpectedly not impaired (Trono et al., 2011). The inhibition by ATP may represent a brake able to finely regulate the $\mathrm{K}^{+}$cycle, so that $\Delta \Psi$ is strongly decreased, but ATP synthesis is anyhow preserved, as explained by the "controlled collapse" reported in Figure 3. This is a central point in cell defense; in this respect, the need of energy for stress protection and maintenance of tissue functional state under water limiting conditions has been underlined very recently (Simova-Stoilova et al., 2015).

When the level of stress becomes severe (Figure 4C), ROS production further increases (+120\%) (Trono et al., 2004). At the same time, a notable increase (up to about 25-fold) of FFAs is observed (Laus et al., 2011), that derives from a doubled activity of the mitochondrial PLA 2 (Trono et al., 2013). Under these conditions, the balance among PmitoK $_{\mathrm{ATP}}$ modulators favors a stronger channel activation by ROS and FFAs/acyl-CoAs over an inhibition by ATP. Consistently, compared to the control, a 300\% and $400 \%$ increase in channel activity was measured under $\mathrm{NaCl}$ and mannitol severe stress, respectively (Trono et al., 2004). This

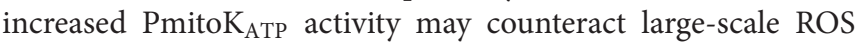
production as reported above, but a concomitant $\Delta \Psi$ collapse is observed. Under these conditions, the fully open channel strongly decreases ATP synthesis (up to about a fifth with respect to a condition of inactive channel), but not completely impairs it (Trono et al., 2011), so that a $50-60 \%$ of ATP content was preserved (Soccio et al., 2013). As for mitochondrial integrity, interestingly, concurrent inhibition of PIMAC by FFAs prevents large amplitude swelling of mitochondria due to PmitoK $\mathrm{ATP}_{\mathrm{AT}}$ activation, thus avoiding outer membrane rupture (Laus et al., 2008).

On the whole, PmitoK $\mathrm{K}_{\mathrm{ATP}}$ appears to be unique among dissipative systems. DWM also possess a very active PUCP and AOX that participate in the control of ROS production, with a cross regulation between PmitoK $\mathrm{ATP}_{\mathrm{AT}}$ and PUCP, as well as a clear role of AOX in green tissues (Pastore et al., 2001, 2007; Trono et al., 2006). However, although both uncoupling 

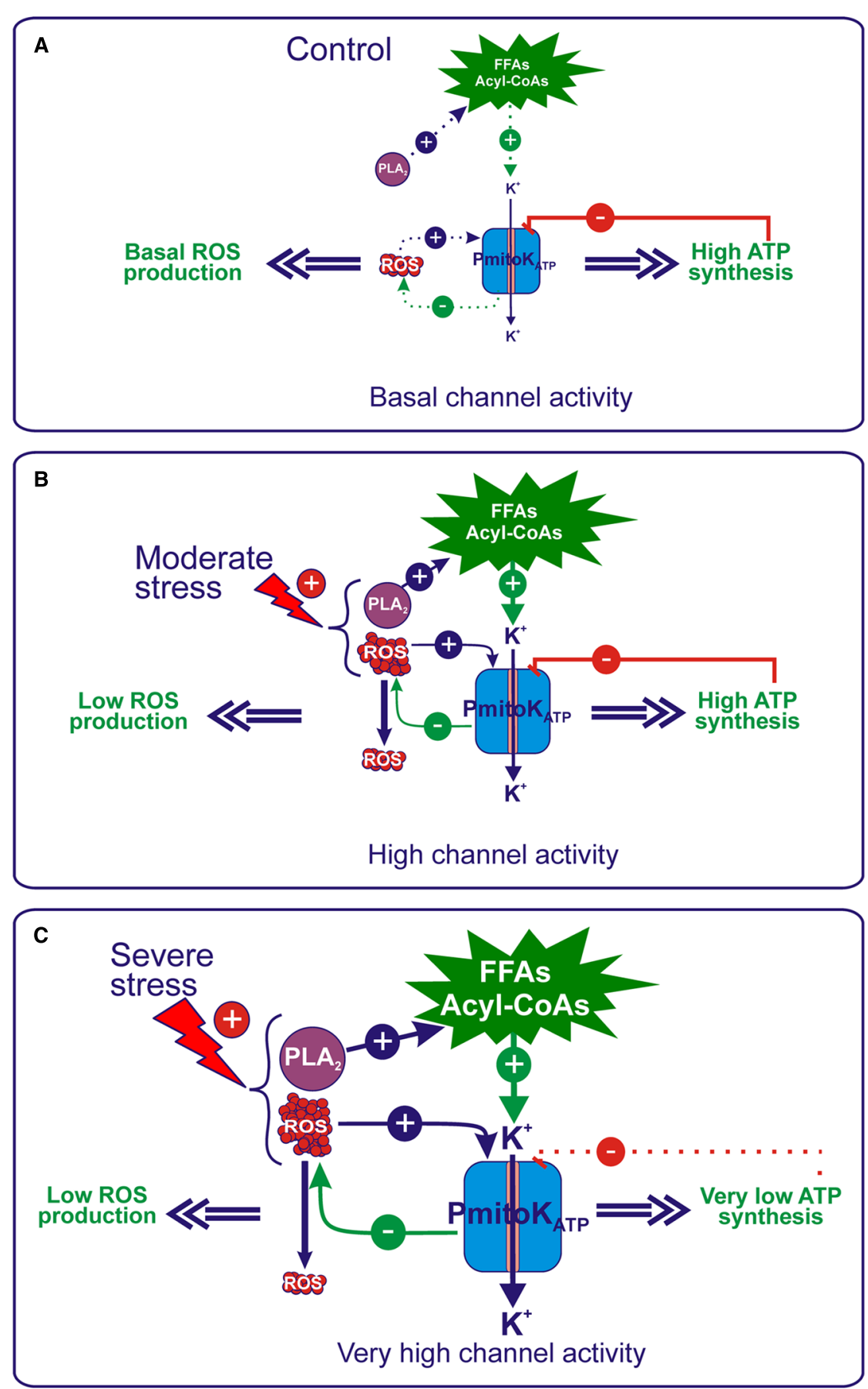

FIGURE 4 | Regulation of ROS production and ATP synthesis by PmitoK ATP under control and hyperosmotic stress conditions. (A) Under control conditions, a basal production of activators occurs, whereas ATP is produced at high level; as a consequence, in the balance of modulators, ATP inhibition of the PmitoK $_{\text {ATP }}$ activity prevails, thus allowing only a basal channel activity. (B) Under moderate stress conditions, an increase in the mitochondrial generation of ROS occurs that activates PmitoK ${ }_{\text {ATP }}$, which, in turn, according to a feedback mechanism, may dampen excess ROS production. Moreover, an activation of the mitochondrial PLA $A_{2}$ also occurs, that may increase the in vivo production of FFAs/acyl-CoAs, which further enhance channel activation. On the other hand, channel inhibition by ATP may represent a brake able to finely regulate the $\mathrm{K}^{+}$cycle, so that $\Delta \Psi$ is strongly decreased to control ROS, but the ATP synthesis is not impaired. In this manner, PmitoK ATP $_{\text {mets }}$ the cell needs, i.e., to dampen harmful ROS production to curtail oxidative stress and, at the same time, to preserve energy to counteract stress. (C) Severe stress conditions determine a further increase in the ROS generation, as well as in the PLA 2 activity, which, in turn, may increase the in vivo production of FFAs/acyl-CoAs. Under these conditions, the balance between channel modulators favors stronger channel activation by activators over inhibition by ATP. This further increased PmitoK ${ }_{\text {ATP }}$ activity determines a $\Delta \Psi$ collapse able to counteract large-scale ROS production, but, in this case, it leads to a strong decrease in the ATP synthesis, although not complete impairment is observed. For details, see the text. The continuous or dotted arrows refer to a more or less active pathway, respectively. 
by PUCP and non-coupling by AOX may dampen superoxide anion production, this control is paid in terms of loss of ATP synthesis (Pastore et al., 2000, 2001, 2007; Trono et al., 2004). On the contrary, PmitoK $\mathrm{ATP}_{\mathrm{AT}}$ may balance ROS control and mitochondrial bioenergetics in a crucial moment by preserving ATP synthesis to defend cell; so, this complex basic mechanism may adapt cellular bioenergetics to changing environmental conditions and may oppose environmental/oxidative stress. To date, it is unknown whether this defense mechanism that involves

\section{REFERENCES}

Alberici, L. C., Oliveira, H. C., Paim, B. A., Mantello, C. C., Augusto, A. C., Zecchin, K. G., et al. (2009). Mitochondrial ATP-sensitive $\mathrm{K}^{+}$channels as redox signals to liver mitochondria in response to hypertriglyceridemia. Free Radic. Biol. Med. 47, 1432-1439. doi: 10.1016/j.freeradbiomed.2009.08.013

Alberici, L. C., Paim, B. A., Zecchin, K. G., Mirandola, S. R., Pestana, C. R., Castilho, R. F., et al. (2013). Activation of the mitochondrial ATP-sensitive $\mathrm{K}^{+}$channel reduces apoptosis of spleen mononuclear cells induced by hyperlipidemia. Lipids Health Dis. 12, 87. doi: 10.1186/1476-511X-12-87

Alscher, R. G., Donahue, J. L., and Cramer, C. L. (1997). Reactive oxygen species and antioxidants: relationships in green cells. Physiol. Plant. 100, 224-233. doi: 10.1034/j.1399-3054.1997.1000203.x

Bernardi, P. (1999). Mitochondrial transport of cations: channels, exchangers, and permeability transition. Physiol. Rev. 79, 1127-1155.

Blokhina, O., and Fagerstedt, K. V. (2010). Reactive oxygen species and nitric oxide in plant mitochondria: origin and redundant regulatory systems. Physiol. Plant. 138, 447-462. doi: 10.1111/j.1399-3054.2009.01340.x

Bränström, R., Leibiger, I. B., Leibiger, B., Klement, G., Nilsson, J., Arhem, P., et al. (2007). Single residue (K332A) substitution in Kir6.2 abolishes the stimulatory effect of long-chain acyl-CoA esters: indications for a long chain acyl-CoA ester binding motif. Diabetologia 50, 1670-1677. doi: 10.1007/s00125-007-0697-x

Buschmann, P. H., Vaidyanathan, R., Gassmann, W., and Schroeder, J. I. (2000). Enhancement of $\mathrm{Na}^{+}$uptake currents, time-dependent inward-rectifying $\mathrm{K}^{+}$ channel currents, and $\mathrm{K}^{+}$channel transcripts by $\mathrm{K}^{+}$starvation in wheat root cells. Plant Physiol. 122, 1387-1397. doi: 10.1104/pp.122.4.1387

Casolo, V., Braidot, E., Chiandussi, E., Vianello, A., and Macrì, F. (2003). K ${ }^{+}$ATP channel opening prevents succinate-dependent $\mathrm{H} 2 \mathrm{O} 2$ generation by plant mitochondria. Physiol. Plant. 118, 313-318.

Casolo, V., Petrussa, E., Krajňáková, J., Macrì, F., and Vianello, A. (2005). Involvement of the mitochondrial $\mathrm{K}^{+} \mathrm{ATP}$ channel in $\mathrm{H} 2 \mathrm{O} 2$ or NO-induced programmed death of soybean suspension cell cultures. J. Exp. Bot. 56, 997-1006. doi: 10.1093/jxb/eri093

Castrejón, V., Parra, C., Moreno, R., Pena, A., and Uribe, S. (1997). Potassium collapses the $\Delta P$ in yeast mitochondria while the rate of ATP synthesis is inhibited only partially: modulation by phosphate. Arch. Biochem. Biophys. 346, 37-44. doi: 10.1006/abbi.1997.0273

Chen, J., Xiong, D.-Y., Wang, W.-H., Hu, W.-J., Simon, M., Xiao, Q., et al. (2013). Nitric oxide mediates root $\mathrm{K}^{+} / \mathrm{Na}^{+}$balance in a mangrove plant, Kandelia obovata, by enhancing the expression of AKT1-type $\mathrm{K}^{+}$channel and $\mathrm{Na}^{+} / \mathrm{H}^{+}$antiporter under high salinity. PLoS ONE 8:e71543. doi: 10.1371/journal.pone. 0071543

Chiandussi, E., Petrussa, E., Macrì, F., and Vianello, A. (2002). Modulation of a plant mitochondrial $\mathrm{K}^{+}$ATP channel and its involvement in cytochrome $\mathrm{c}$ release. J. Bioenerg. Biomembr. 34, 177-184. doi: 10.1023/A:1016079319070

Costa, A. D., and Garlid, K. D. (2008). Intramitochondrial signaling: interactions among mitoKATP, PKC, ROS, and MPT. Am. J. Physiol. Heart. Circ. Physiol. 295, H874-H882. doi: 10.1152/ajpheart.01189.2007

Czyz, A., Szewczyk, A., Nalecz, M. J., and Wojtczak L. (1995). The role of mitochondrial potassium fluxes in controlling the protonmotive force in energized mitochondria. Biochem. Biophys. Res. Commun. 210, 98-104. doi: 10.1006/bbrc. 1995.1632

De Marchi, U., Checchetto, V., Zanetti, M., Teardo, E., Soccio, M., Formentin, E., et al. (2010). ATP-sensitive cation-channel in wheat (Triticum durum Desf.): identification and characterization of a plant mitochondrial channel by patchclamp. Cell. Physiol. Biochem. 26, 975-982. doi: 10.1159/000324010
PmitoK $_{\text {ATP }}$ in DWM may be operating in other plant species. Further investigations about this aspect should be worthwhile.

\section{AUTHOR CONTRIBUTIONS}

DT, MNL, and MS reviewed relevant literature and wrote the manuscript; MA supported analysis of literature and co-wrote the manuscript; DP supervised the review and co-wrote the manuscript.

Demidchik, V., Cuin, T. A., Svistunenko, D., Smith, S. J., Miller, A. J., Shabala, S., et al. (2010). Arabidopsis root $\mathrm{K}^{+}$-efflux conductance activated by hydroxyl radicals: single-channel properties, genetic basis and involvement in stressinduced cell death. J. Cell Sci. 123, 1468-1479. doi: 10.1242/jcs.064352

Diolez, P., and Moreau, F. (1985). Correlations between ATP synthesis, membrane potential and oxidation rate in plant mitochondria. Biochim. Biophys. Acta 806, 56-63. doi: 10.1016/0005-2728(85)90081-7

Douce, R. (ed.) (1985). "Composition and function of plant mitochondrial membranes," in Mitochondria in Higher Plants. Structure, Function, and Biogenesis, (Orlando: Academic Press), 125-146.

Echtay, K. S. (2007). Mitochondrial uncoupling proteins: what is their physiological role? Free Radic. Biol. Med. 43, 1351-1371. doi: 10.1016/j. freeradbiomed.2007.08.011

Facundo, H. T., de Paula, J. G., and Kowaltowski, A. J. (2005). Mitochondrial ATP-sensitive $\mathrm{K}^{+}$channels prevent oxidative stress, permeability transition and cell death. J. Bioenerg. Biomembr. 37, 75-82. doi: 10.1007/s10863-0054130-1

Facundo, H. T., de Paula, J. G., and Kowaltowski, A. J. (2007). Mitochondrial ATP-sensitive $\mathrm{K}^{+}$channels are redox-sensitive pathways that control reactive oxygen species production. Free Radic. Biol. Med. 42, 1039-1048. doi: 10.1016/j.freeradbiomed.2007.01.001

Ferranti, R., da Silva, M. M., and Kowaltowski, A. J. (2003). Mitochondrial ATPsensitive $\mathrm{K}^{+}$channel opening decreases reactive oxygen species generation. FEBS Lett. 536, 51-55. doi: 10.1016/S0014-5793(03)00007-3

Flagella, Z., Trono, D., Pompa, M., Di Fonzo, N., and Pastore, D. (2006). Seawater stress applied at germination affects mitochondrial function in durum wheat (Triticum durum) early seedlings. Funct. Plant Biol. 33, 357-366. doi: 10.1071/FP05244

Foyer, C. H., Lescure, J. C., Lefebvre, C., Morot-Gaudry, J. F., Vincentz, M., and Vaucheret, H. (1994). Adaptations of photosynthetic electron transport, carbon assimilation, and carbon partitioning in transgenic Nicotiana plumbaginifolia plants to changes in nitrate reductase activity. Plant Physiol. 104, 171-178.

Fratianni, A., Pastore, D., Pallotta, M. L., Chiatante, D., and Passarella, S. (2001). Increase of membrane permeability of mitochondria isolated from water stress adapted potato cells. Biosci. Rep. 21, 81-91. doi: 10.1023/A:1010490219357

Frungillo, L., de Oliveira, J. F., Saviani, E. E., Oliveira, H. C., Martínez, M. C., and Salgado, I. (2013). Modulation of mitochondrial activity by S-nitrosoglutathione reductase in Arabidopsis thaliana transgenic cell lines. Biochim. Biophys. Acta 1827, 239-247. doi: 10.1016/j.bbabio.2012.11.011

Garcia-Mata, C., Wang, J., Gajdanowicz, P., Gonzalez, W., Hills, A., Donald, N., et al. (2010). A minimal cysteine motif required to activate the SKOR $\mathrm{K}^{+}$ channel of Arabidopsis by the reactive oxygen species H2O2. J. Biol. Chem. 285, 29286-29294. doi: 10.1074/jbc.M110.141176

Garlid, A. O., Jaburek, M., Jacobs, J. P., and Garlid, K. D. (2013). Mitochondrial reactive oxygen species: which ROS signals cardioprotection? Am. J. Physiol. Heart Circ. Physiol. 305, H960-H968. doi: 10.1152/ajpheart.00858.2012

Garlid, K. D. (1996). Cation transport in mitochondria-the potassium cycle. Biochim. Biophys. Acta 1275, 123-126. doi: 10.1016/0005-2728(96)00061-8

Garlid, K. D., and Paucek, P. (2003). Mitochondrial potassium transport: the $\mathrm{K}^{+}$ cycle. Biochim. Biophys. Acta 1606, 23-41. doi: 10.1016/S0005-2728(03)00108-7

Gout, E., Bligny, R., and Douce, R. (1992). Regulation of intracellular $\mathrm{pH}$ values in higher plant cells. Carbon-13 and phosphorus-31 nuclear magnetic resonance studies. J. Biol. Chem. 267, 13903-13909.

Halle-Smith, S. C., Murray, A. G., and Selwyn, M. J. (1988). Palmitoyl-CoA inhibits the mitochondrial inner membrane anion-conducting channel. FEBS Lett. 236, 155-158. doi: 10.1016/0014-5793(88)80305-3 
Heberle, J., Riesle, J., Thiedemann, G., Oesterhelt, D., and Dencher, N. A. (1994). Proton migration along the membrane surface and retarded surface to bulk transfer. Nature 370, 379-382. doi: 10.1038/370379a0

Hourton-Cabassa, C., Rita Matos, A., Zachowski, A., and Moreau, F. (2004). The plant uncoupling protein homologues: a new family of energy-dissipating proteins in plant mitochondria. Plant Physiol. Biochem. 42, 283-290. doi: 10.1016/j.plaphy.2004.01.007

Huang, X., von Rad, U., and Durner, J. (2002). Nitric oxide induces transcriptional activation of the nitric oxide-tolerant alternative oxidase in Arabidopsis suspension cells. Planta 215, 914-923. doi: 10.1007/s00425-002$0828-\mathrm{z}$

Igamberdiev, A. U., and Kleczkowski, L. A. (2003). Membrane potential, adenylate levels and $\mathrm{Mg}_{2}{ }^{+}$are interconnected via adenylate kinase equilibrium in plant cells. Biochim. Biophys. Acta 1607, 111-119. doi: 10.1016/j.bbabio.2003.09.005

Igamberdiev, A. U., Ratcliffe, R. G., and Gupta, K. J. (2014). Plant mitochondria: source and target for nitric oxide. Mitochondrion 19, 329-333. doi: 10.1016/j.mito.2014.02.003

Koszela-Piotrowska, I., Matkovic, K., Szewczyk, A., and Jarmuszkiewicz, W. (2009). A large-conductance calcium-activated potassium channel in potato (Solanum tuberosum) tuber mitochondria. Biochem. J. 424, 307-316. doi: 10.1042/BJ20090991

Kowaltowski, A. J., de Souza-Pinto, N. C., Castilho, R. F., and Vercesi, A. E. (2009). Mitochondria and reactive oxygen species. Free Radic. Biol. Med. 47, 333-343. doi: 10.1016/j.freeradbiomed.2009.05.004

Kowaltowski, A. J., Seetharama, S., Paucek, P., and Garlid, K. D. (2001). Bioenergetic consequences of opening the ATP-sensitive $\mathrm{K}^{+}$channel of heart mitochondria. Am. J. Physiol. Heart Circ. Physiol. 280, 649-657.

Krömer, S., and Heldt, H. W. (1991). Respiration of pea leaf mitochondria and redox transfer between the mitochondrial and extramitochondrial compartment. Biochim. Biophys. Acta 1057, 42-50. doi: 10.1016/S0005-2728(05)80082-9

Krulwich, T. A. (1995). Alkaliphiles: "basic" molecular problems of $\mathrm{pH}$ tolerance and bioenergetics. Mol. Microbiol. 15, 403-410. doi: 10.1111/j.13652958.1995.tb02253.x

Larson, T. R., and Graham, I. A. (2001). Technical Advance: a novel technique for the sensitive quantification of acyl CoA esters from plant tissues. Plant J. 25, 115-125. doi: 10.1111/j.1365-313X.2001.00929.x

Laus, M. N., Soccio, M., Trono, D., Cattivelli, L., and Pastore, D. (2008). Plant Inner Membrane Anion Channel (PIMAC) function in plant mitochondria. Plant Cell Physiol. 49, 1039-1055. doi: 10.1093/pcp/pcn082

Laus, M. N., Soccio, M., Trono, D., Liberatore, M. T., and Pastore, D. (2011). Activation of the plant mitochondrial potassium channel by free fatty acids and acyl-CoA esters: possible defence mechanism in the response to hyperosmotic stress. J. Exp. Bot. 62, 141-154. doi: 10.1093/jxb/erq256

Lee, Y., Lee, H. J., Crain, R. C., Lee, A., and Korn, S. J. (1994). Polyunsaturated fatty acids modulate stomatal aperture and two distinct $\mathrm{K}^{+}$channel currents in guard cells. Cell. Signal. 6, 181-186. doi: 10.1016/0898-6568(94)90075-2

Leigh, R. A., and Wyn Jones, R. G. (1984). A hypothesis relating critical potassium concentrations for growth to the distribution and functions of this ion in the plant cell. New Phytol. 97, 1-14. doi: 10.1111/j.1469-8137.1984.tb 04103.x

Liu, G. X., Hanley, P. J., Ray, J., and Daut, J. (2001). Long-chain acyl-coenzyme A esters and fatty acids directly link metabolism to KATP channels in the heart. Circ. Res. 88, 918-924. doi: 10.1161/hh0901.089881

Liu, X., Gong, X., Hicks, D. B., Krulwich, T. A., Yu, L., and Yu, C. A. (2007). Interaction between the cytochrome caa3 and F1F0-ATP synthase of alkaliphilic Bacillus pseudofirmus OF4 is demonstrated by saturation transfer electron paramagnetic resonance and differential scanning calorimetry assays. Biochemistry 46, 306-313. doi: 10.1021/bi0619167

Ljubkovic, M., Shi, Y., Cheng, Q., Bosnjak, Z., and Jiang, M. T. (2007). Cardiac mitochondrial ATP-sensitive potassium channel is activated by nitric oxide in vitro. FEBS Lett. 581, 4255-4259. doi: 10.1016/j.febslet.2007.07.071

Matkovic, K., Koszela-Piotrowska, I., Jarmuszkiewicz, W., and Szewczyk, A. (2011). Ion conductance pathways in potato tuber (Solanum tuberosum) inner mitochondrial membrane. Biochim. Biophy. Acta 1807, 275-285. doi: 10.1016/j.bbabio.2010.12.001

Michel, H., and Oesterhelt, D. (1980). Electrochemical proton gradient across the cell membrane of Halobacterium halobium: comparison of the light-induced increase with the increase of intracellular adenosine triphosphate under steadystate illumination. Biochemistry 19, 4615-4619. doi: 10.1021/bi00561a012
Millar, A. H., and Day, D. A. (1996). Nitric oxide inhibits the cytochrome oxidase but not the alternative oxidase of plant mitochondria. FEBS Lett. 398, 155-158. doi: 10.1016/S0014-5793(96)01230-6

Møller, I. M. (2001). Plant mitochondria and oxidative stress: electron transport, NADPH turnover, and metabolism of reactive oxygen species. Ann. Rev. Plant Phys. Plant Mol. Biol. 52, 561-591. doi: 10.1146/annurev.arplant.52. 1.561

Olszewska, A., Bednarczyk, P., Siemen, D., and Szewczyk, A. (2014). Modulation of the mitochondrial large-conductance calcium-regulated potassium channel by polyunsaturated fatty acids. Biochim. Biophys. Acta 1837, 1602-1610. doi: 10.1016/j.bbabio.2014.07.010

Ort, D. R., Dilley, R. A., and Good, N. E. (1976). Photophosphorylation as a function of illumination time. II. Effects of permeant buffers. Biochim. Biophys. Acta 449, 108-124. doi: 10.1016/0005-2728(76)90011-6

Pastore, D., Di Pede, S., and Passarella, S. (2003). Isolated durum wheat mitochondria and potato cell mitochondria oxidize externally added NADH mostly via the malate/oxaloacetate shuttle with a rate that depends on the carrier-mediated transport. Plant Physiol. 133, 2029-2039. doi: 10.1104/pp.103. 028548

Pastore, D., Fratianni, A., Di Pede, S., and Passarella, S. (2000). Effects of fatty acids, nucleotides and reactive oxygen species on durum wheat mitochondria. FEBS Lett. 470, 88-92. doi: 10.1016/S0014-5793(00)01292-8

Pastore, D., Laus, M. N., Di Fonzo, N., and Passarella S. (2002). Reactive oxygen species inhibit the succinate oxidation-supported generation of membrane potential in wheat mitochondria. FEBS Lett. 516, 15-19. doi: 10.1016/S00145793(02)02454-7

Pastore, D., Soccio, M., Laus, M. N., and Trono, D. (2013). The uniqueness of the plant mitochondrial potassium channel. BMB Rep. 46, 391-397. doi: 10.5483/BMBRep.2013.46.8.075

Pastore, D., Stoppelli, M. C., Di Fonzo, N., and Passarella, S. (1999). The existence of the $\mathrm{K}^{+}$channel in plant mitochondria. J. Biol. Chem. 274, 26683-26690. doi: $10.1074 / j b c .274 .38 .26683$

Pastore, D., Trono, D., Laus, M. N., Di Fonzo, N., and Flagella, Z. (2007). Possible plant mitochondria involvement in cell adaptation to drought stress. A case study: durum wheat mitochondria. J. Exp. Bot. 58, 195-210. doi: 10.1093/jxb/erl273

Pastore, D., Trono, D., Laus, M. N., Di Fonzo, N., and Passarella, S. (2001). Alternative oxidase in durum wheat mitochondria. Activation by pyruvate, hydroxypyruvate, and glyoxylate and physiological role. Plant Cell Physiol. 42, 1373-1382. doi: 10.1093/pcp/pce174

Paucek, P., Dolgacova, L., and Garlid, K. D. (2002). Purification and reconstitution of KATP channel (PmitoKATP) of plant mitochondria. Biophys. J. 82, 109.

Paucek, P., Mironova, G., Mahdi, F., Beavis, A. D., Woldegiorgis, G., and Garlid, K. D. (1992). Reconstitution and partial purification of the glibenclamide-sensitive, ATP-dependent $\mathrm{K}^{+}$channel from rat liver and beef heart mitochondria. J. Biol. Chem. 267, 26062-26069.

Paucek, P., Yarov-Yarovoy, V., Sun, X., and Garlid, K. D. (1996). Inhibition of the mitochondrial KATP channel by long-chain acyl-CoA esters and activation by guanine nucleotides. Biol. Chem. 271, 32084-32088. doi: 10.1074/jbc.271.50.32084

Paventi, G., Pastore, D., Bobba, A., Pizzuto, R., Di Pede, S., and Passarella, S. (2006). Plant uncoupling protein in mitochondria from aged-dehydrated slices of Jerusalem artichoke tubers becomes sensitive to superoxide and to hydrogen peroxide without increase in protein level. Biochimie 88, 179-188. doi: 10.1016/j.biochi.2005.07.009

Petrussa, E., Bertolini, A., Krajnáková, J., Casolo, V., Macrì, F., and Vianello, A. (2008a). Isolation of mitochondria from embryogenic cultures of Picea abies (L.) Karst. and Abies cephalonica Loud.: characterization of a $\mathrm{K}^{+}$ATP channel. Plant Cell Rep. 27, 137-146. doi: 10.1007/s00299-007-0436-2

Petrussa, E., Casolo, V., Peresson, C., Krajnáková, J., Macrì, F., and Vianello, A. (2008b). Activity of a $\mathrm{K}^{+}$ATP channel in Arum spadix mitochondria during thermogenesis. J. Plant Physiol. 165, 1360-1369. doi: 10.1016/j.jplph.2007. 10.012

Petrussa, E., Casolo, V., Braidot, E., Chiandussi, E., Macrì, F., and Vianello, A. (2001). Cyclosporin A induces the opening of a potassium selective channel in higher plant mitochondria. J. Bioenerg. Biomembr. 33, 107-117. doi: 10.1023/A:1010796314162

Petrussa, E., Casolo, V., Peresson, C., Braidot, E., Vianello, A., and Macrì, F. (2004). The $\mathrm{K}^{+}$ATP channel is involved in a low-amplitude permeability transition 
in plant mitochondria. Mitochondrion 3, 297-307. doi: 10.1016/j.mito.2004. 01.002

Roby, C., Martin, J. B., Bligny, R., and Douce, R. (1987). Biochemical changes during sucrose deprivation in higher plant cells. Phosphorous-31 nuclear magnetic resonance studies. J. Biol. Chem. 262, 5000-5007.

Ruy, F., Vercesi, A. E., Andrade, P. B. M., Bianconi, M. L., Chaimovich, H., and Kowaltowski, A. J. (2004). A highly active ATP-insensitive $\mathrm{K}^{+}$import pathway in plant mitochondria. J. Bioenerg. Biomembr. 36, 195-202. doi: 10.1023/B:JOBB.0000023623.70126.04

Scandalios, J. G. (1993). Oxygen stress and superoxide dismutases. Plant Physiol. $101,7-12$.

Schönfeld, P., Gerke, S., Bohnensack, R., and Wojtczak, L. (2003). Stimulation of potassium cycling in mitochondria by long-chain fatty acids. Biochim. Biophy. Acta 1604, 125-133. doi: 10.1016/S0005-2728(03)00043-4

Schönfeld, P., Sayeed, I., Bohnensack, R., and Siemen, D. (2004). Fatty acids induce chloride permeation in rat liver mitochondria by activation of the inner membrane anion channel (IMAC). J. Bioenerg. Biomembr. 36, 241-248. doi: 10.1023/B:JOBB.0000031975.72350.c6

Schulze, D., Rapedius, M., Krauter, T., and Baukrowitz, T. (2003). Long-chain acylCoA esters and phosphatidylinositol phosphates modulate ATP inhibition of KATP channels by the same mechanism. J. Physiol. 552, 357-367.

Simova-Stoilova, L. P., Romero-Rodríguez, M. C., Sánchez-Lucas, R., NavarroCerrillo, R. M., Alberto Medina-Aunon, J., and Jorrín-Novo, J. V. (2015). 2-DE proteomics analysis of drought treated seedlings of Quercus ilex supports a root active strategy for metabolic adaptation in response to water shortage. Front. Plant Sci. 6:627. doi: 10.3389/fpls.2015.00627

Skulachev, V. P. (1994). The latest news of the sodium world. Biochim. Biophys. Acta 1187, 216-221. doi: 10.1016/0005-2728(94)90114-7

Skulachev, V. P. (1998). Uncoupling: new approaches to an old problem of bioenergetics. Biochim. Biophys. Acta 1363, 100-124. doi: 10.1016/S00052728(97)00091-1

Sluse, F. E., Almeida, A. M., Jarmuszkiewicz, W., and Vercesi, A. E. (1998). Free fatty acids regulate the uncoupling protein and alternative oxidase activities in plant mitochondria. FEBS Lett. 433, 237-240. doi: 10.1016/S0014-5793(98) 00922-3

Soccio, M., Laus, M. N., Spera, G. P., Trono, D., Pompa, M., Flagella, Z., et al. (2010). Mitochondrial proline oxidation is affected by hyperosmotic stress in durum wheat seedlings. Ann. Appl. Biol. 157, 1-11. doi: 10.1111/j.17447348.2010.00392.x

Soccio, M., Laus, M. N., Trono, D., and Pastore, D. (2013). A new simple fluorimetric method to assay cytosolic ATP content. Application to durum wheat seedlings to assess modulation of mitochondrial potassium channel and uncoupling protein activity under hyperosmotic stress. Biologia $68,421-432$. doi: 10.2478/s11756013-0176-4

Sorgato, M. C., Branca, D., and Ferguson, S. J. (1980). The rate of ATP synthesis by submitochondrial particles can be independent of the magnitude of the protonmotive force. Biochem. J. 188, 945-948. doi: 10.1042/bj1 880945

Sze, H., Padmanaban, S., Cellier, F., Honys, D., Cheng, N.-H., Bock, K. W., et al. (2004). Expression patterns of a novel AtCHX gene family highlight potential roles in osmotic adjustment and $\mathrm{K}^{+}$homeostasis in pollen development. Plant Physiol. 136, 2532-2547. doi: 10.1104/pp.104.046003

Tanaka, N., Fujita, M., Handa, H., Murayama, S., Uemura, M., Kawamura, Y., et al. (2004). Proteomics of the rice cell: systematic identification of the protein populations in subcellular compartments. Mol. Genet. Genomics 271, 566-576. doi: $10.1007 / \mathrm{s} 00438-004-1002-\mathrm{z}$

Tedeschi, H. (2005a). Old and new data, new issues: the mitochondrial $\triangle \Psi . B B A$ Bioenergetics 1709, 195-202. doi: 10.1016/j.bbabio.2005.07.008

Tedeschi, H. (2005b). Reply to David Nicholls' response. BBA Bioenergetics 1710, 66. doi: 10.1016/j.bbabio.2005.10.004

Trono, D., Flagella, Z., Laus, M. N., Di Fonzo, N., and Pastore, D. (2004). The uncoupling protein and the potassium channel are activated by hyperosmotic stress in mitochondria from durum wheat seedlings. Plant Cell Environ. 27, 437-448. doi: 10.1111/j.1365-3040.2003.01162.x
Trono, D., Laus, M. N., Soccio, M., and Pastore, D. (2014). Transport pathwaysproton motive force interrelationship in durum wheat mitochondria. Int. J. Mol. Sci. 15, 8186-8215. doi: 10.3390/ijms15058186

Trono, D., Soccio, M., Laus, M. N., and Pastore, D. (2011). Potassium channeloxidative phosphorylation relationship in durum wheat mitochondria from control and hyperosmotic- stressed seedlings. Plant Cell Environ. 34, 2093-2108. doi: 10.1111/j.1365-3040.2011.02407.x

Trono, D., Soccio, M., Laus, M. N., and Pastore, D. (2013). The existence of phospholipase A2 activity in plant mitochondria and its activation by hyperosmotic stress in durum wheat (Triticum durum Desf.). Plant Sci. 199-200, 91-102. doi: 10.1016/j.plantsci.2012.11.002

Trono, D., Soccio, M., Mastrangelo, A. M., De Simone, V., Di Fonzo, N., and Pastore, D. (2006). The transcript levels of two plant mitochondrial uncoupling protein (pUCP)-related genes are not affected by hyperosmotic stress in durum wheat seedlings showing an increased level of pUCP activity. Biosci. Rep. 26, 251-261. doi: 10.1007/s10540-006-9020-1

Ubl, J. J., Chatton, J. Y., Chen, S., and Stucki, J. W. (1996). A critical evaluation of in situ measurement of mitochondrial electrical potentials in single hepatocytes. Biochim. Biophys. Acta 1276, 124-132. doi: 10.1016/0005-2728(96)00067-9

Vanlerberghe, G. C., and McIntosh, L. (1996). Signals regulating the expression of the nuclear gene encoding alternative oxidase of plant mitochondria. Plant Physiol. 111, 589-595.

Vercesi, A. E., Borecký, J., Maia Ide, G., Arruda, P., Cuccovia, I. M., and Chaimovich, H. (2006). Plant uncoupling mitochondrial proteins. Annu. Rev. Plant Biol. 57, 383-404. doi: 10.1146/annurev.arplant.57.032905.105335

Wagner, A. M. (1995). A role for active oxygen species as second messengers in the induction of alternative oxidase gene expression in Petunia hybrida cells. FEBS Lett. 368, 339-342. doi: 10.1016/0014-5793(95)00688-6

Wan, B., Doumen, C., Duszynski, J., Salama, G., Vary, T. C., and LaNoue, K. F. (1993). Effects of cardiac work on electrical potential gradient across mitochondrial membrane in perfused rat hearts. Am. J. Physiol. 265, H453-H460.

Webster, N. J., Searle, G. J., Lam, P. P. L., Huang, Y. C., Riedel, M. J., Harb, G., et al. (2008). Elevation in intracellular long chain acyl-coenzyme A esters lead to reduced $\beta$-cell excitability via activation of adenosine $5^{\prime}$-triphosphate-sensitive potassium channels. Endocrinology 149, 3679-3687. doi: 10.1210/en.20071138

Xia, J., Kong, D., Xue, S., Tian, W., Li, N., Bao, F., et al. (2014). Nitric oxide negatively regulates AKT1-mediated potassium uptake through modulating vitamin B6 homeostasis in Arabidopsis. Proc. Natl. Acad. Sci. U.S.A. 111, 16196-16201. doi: $10.1073 /$ pnas. 1417473111

Xu, H., Martinoia, E., and Szabo, I. (2015). Organellar channels and transporters. Cell Calcium 58, 1-10. doi: 10.1016/j.ceca.2015.02.006

Zhang, D. X., Chen, Y. F., Campbell, W. B., Zou, A. P., Gross, G. J., and Li, P. L. (2001a). Characteristics and superoxide-induced activation of reconstituted myocardial mitochondrial ATP-sensitive potassium channels. Circ. Res. 89, 1177-1183. doi: 10.1161/hh2401.101752

Zhang, H., Huang, H. M., Carson, R. C., Mahmood, J., Thomas, H. M., and Gibson, G. E. (2001b). Assessment of membrane potentials of mitochondrial populations in living cells. Anal. Biochem. 298, 170-180. doi: 10.1006/abio.2001.5348

Zotova, L., Aleschko, M., Sponder, G., Baumgartner, R., Reipert, S., Prinz, M., et al. (2010). Novel components of an active mitochondrial $\mathrm{K}^{+} / \mathrm{H}^{+}$exchange. J. Biol. Chem. 285, 14399-14414. doi: 10.1074/jbc.M109.059956

Conflict of Interest Statement: The authors declare that the research was conducted in the absence of any commercial or financial relationships that could be construed as a potential conflict of interest.

Copyright $\odot 2015$ Trono, Laus, Soccio, Alfarano and Pastore. This is an open-access article distributed under the terms of the Creative Commons Attribution License (CC $B Y$ ). The use, distribution or reproduction in other forums is permitted, provided the original author(s) or licensor are credited and that the original publication in this journal is cited, in accordance with accepted academic practice. No use, distribution or reproduction is permitted which does not comply with these terms. 